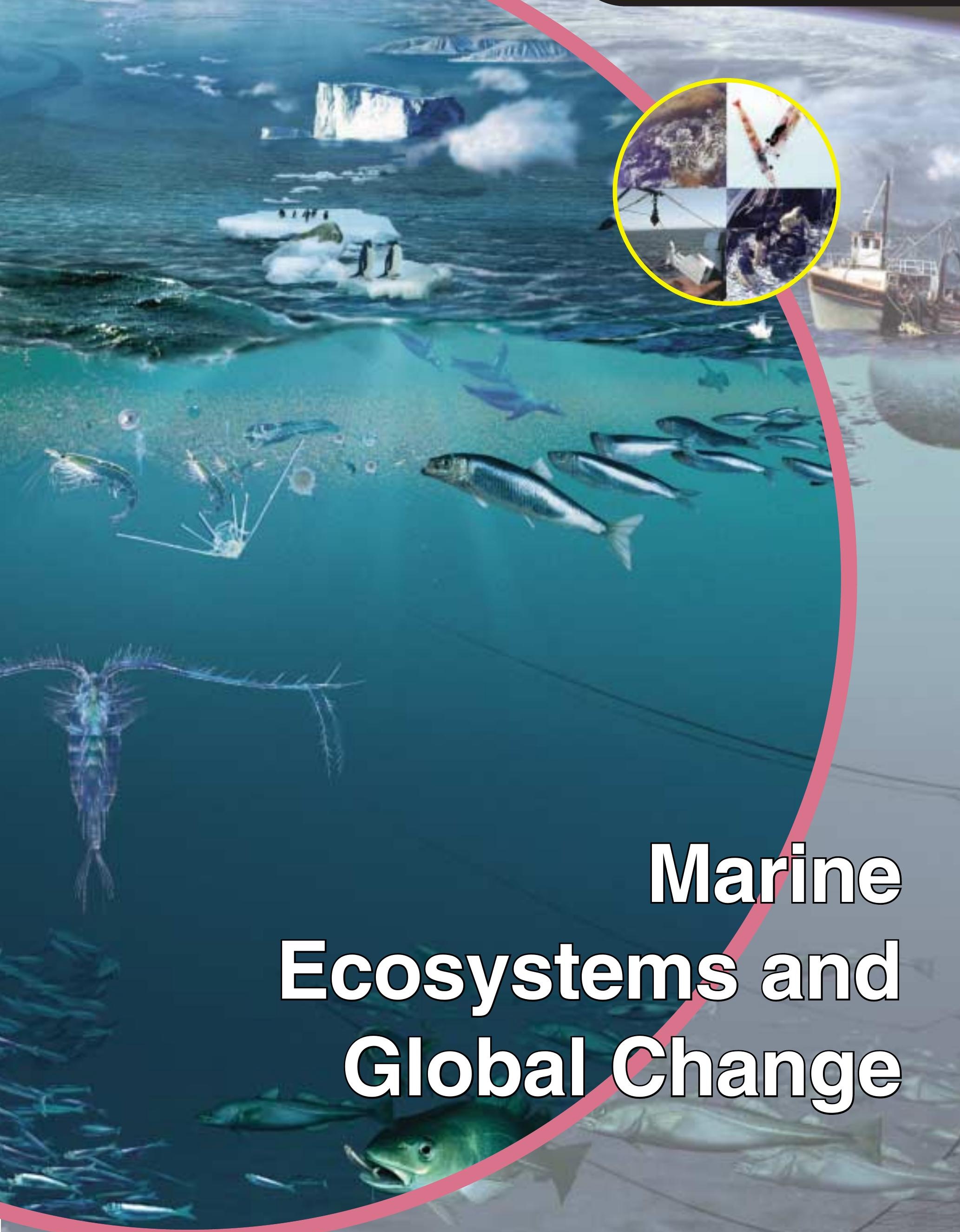




\section{Why GLOBEC?}

The Global Ocean Ecosystem Dynamics Project (GLOBEC) was adopted in 1995 by the International Geosphere-Biosphere Programme as a new Project, with co-sponsorship from the Scientific Committee on Oceanic Research (SCOR) and the Intergovernmental Oceanographic Commission of UNESCO (IOC). Its goal is to "advance our understanding of the structure and functioning of the global ocean ecosystem, and its response to physical forcing, so that a capability can be developed to forecast the responses of the marine ecosystem to global change."

GLOBEC considers global change in the broad sense, encompassing the gradual processes of climate change and its impacts on marine systems, as well as those shorter-term changes resulting from anthropogenic pressures, such as population growth in coastal areas, increased pollution, overfishing, changing fishing practices and changing human use of the seas.

GLOBEC has four detailed scientific objectives:

1. To better understand how multi-scale physical environmental processes force large-scale changes in marine ecosystems.

2. To determine the relationship between structure and dynamics in a variety of oceanic systems which typify significant components of the global ocean ecosystem, with emphasis on individuals and populations of key species and trophodynamic pathways.

3. To determine the impacts of global change on stock dynamics using coupled physical, biological and chemical models linked to appropriate observation systems, and to develop the capability to predict future impacts.

4. To determine how changing marine ecosystems will affect the Earth System by identifying and quantifying feedback mechanisms. 
2 - Foreword

3 - Oceans of Change

5 - Global Processes Impacting the Oceans

Climate forcing of ocean ecosystems

Introduction of non-indigenous species

Intensive fishing

14 - Changing Marine Ecosystem Dynamics

Changes in transport processes: migration and survival of the Japanese eel

Changes in trophic links: the North Atlantic Calanus-cod story

Changes in top predator dynamics: North Pacific salmon.

Changes in ecosystem biodiversity: patterns in northeastern

Atlantic zooplankton communities.

Changes in ecosystem structure and dynamics: regime shifts

23 - Detecting Changes in the Oceans

Molecular biology and genetic techniques

New video technologies

New hydroacoustic tools

Modelling: from the individual to populations

30 - Emerging Issues

31 - About GLOBEC 
The ocean is a vital component of the metabolism of the Earth and plays a key role in global change. In fact, the oceans cover so much of the Earth's surface that our planet has been described as the Water Planet, and it could be argued that its most extensive ecosystems are marine. Marine ecosystems are inextricably involved in the physical, chemical, biological and societal processes of global change. It is impossible to describe and understand the Earth system without understanding the ocean, the special characteristics of the environment that it provides for life, the changes that it is undergoing and the manner in which these changes interact with the total Earth System. Understanding the functioning of marine ecosystems and how they respond to global change is also essential in order to effectively manage global marine living resources, such as fisheries.

The upper trophic levels of marine ecosystems-fish, whales, seals and seabirds-are all prominent in the public eye. Fish, in particular, provide the living marine resources which have sustained human communities over centuries, but which are now increasingly under threat. However, the food webs sustaining these larger visible components of marine ecosystems, composed of small microscopic organisms like plankton, are less well known. The diversity and interactions of plankton are complex. How they will be affected by changes in ocean physics, mixing, currents and circulation resulting from global change is the major challenge that the GLOBEC project is addressing. Similarly, human exploitation of higher trophic levels through fishing has a major impact on marine ecosystems, which may, in turn, affect the Earth System through changes in ecosystem structure and function.

The GLOBEC project is an international response to the need to understand how global change will affect the abundance, diversity and productivity of marine populations, from zooplankton to fish, that comprise a major component of oceanic ecosystems. GLOBEC's goal is to advance our understanding of the structure and functioning of such ecosystems, their major subsystems, and responses to physical forcing so that a capability can be developed to forecast the response of marine ecosystems to global change.

This volume in the IGBP Science Series, "Marine Ecosystems and Global Change”, gives topical examples of the scientific problems that GLOBEC is tackling, the innovative approaches adopted, and some selected scientific achievements. It has been written at a time when GLOBEC is in the mid-phase of its implementation. The ultimate achievements of GLOBEC research will be presented in a final synthesis at the end of the project. 


\title{
Oceans of Change
}

\author{
Changes are occurring throughout the Earth System, including \\ in the oceans. These changes are increasingly driven by human \\ activities. We need to understand how ocean ecosystems react \\ to global change in order to understand the consequences for \\ the functioning of the oceans and to manage ocean resources \\ sustainably.
}

The oceans are constantly subject to change. Over days, years and even millennia, changes caused by climate shifts, alterations in ocean currents and, more recently, human activities have a dramatic impact on all marine life.

Source: Clare Bradshaw.
UNTIL VERY RECENTLY human activities have been an insignificant force in the dynamics of the Earth. However, the magnitude, scale and pace of human-induced change over the last century have been unprecedented: human population has increased by a factor of four; industrial output has multiplied by forty; nearly $50 \%$ of all land surface has been transformed by humans; and present levels of atmospheric greenhouse gases have not been exceeded for at least 400,000 years (Fig. 1). Such dominance of human activity over nature has led to the suggestion that we are entering the Antbropocene era.The impact on marine biological populations has also been substantial. Over $50 \%$ of all mangroves have been removed, wetlands have shrunk by a third and over $50 \%$ of all marine fisheries are overexploited or have reached maximum exploitation levels.
The Earth's biological systems have always been in a constant state of evolution and change, but the causes and consequences of change in the Antbropocene are difficult to ascertain. Can we separate human-induced changes from changes resulting from natural climate variability? Does climate change influence climate variability? Can we identify overfishing or pollution as responsible for some of the changes observed in the oceans? Can we quantify change? The Global Ocean Ecosystem Dynamic (GLOBEC) project follows an interdisciplinary approach to better understand marine ecosystems and how they are changing (Fig. 2).The ultimate objective is to provide scientific underpinning for the development of sustainable management practices for the use and exploitation of marine ecosystems. 

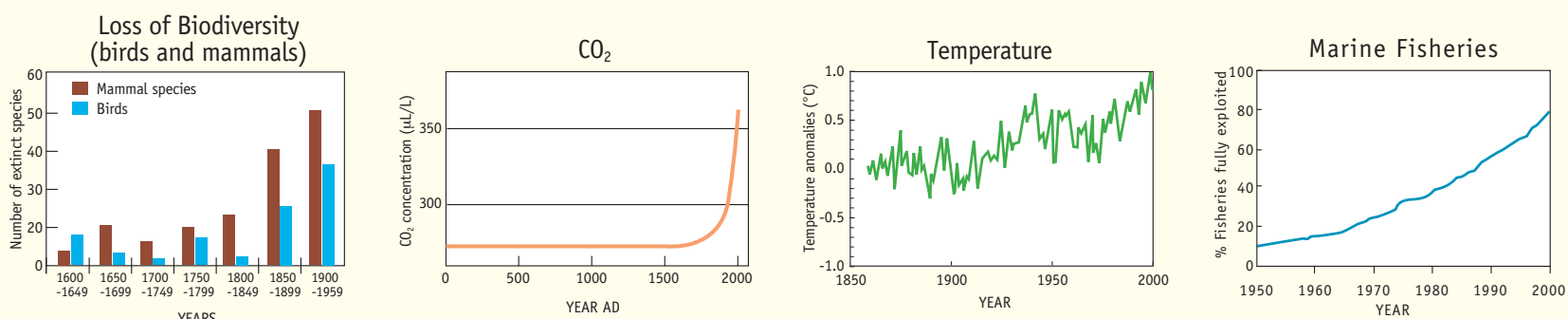

Figure 1 The magnitude, scale and pace of global change over the last century are unprecedented, and extend into every part of the Earth System.

Source: Adapted from Reid and Miller (1989) WRI. Adapted from Vitousek et al. (1994) Ecology 75: 1861-1876. Adapted from FAO (2000) The State of the world's Fisheries and aquaculture. UN, Rome.

\section{Global change affects marine populations}

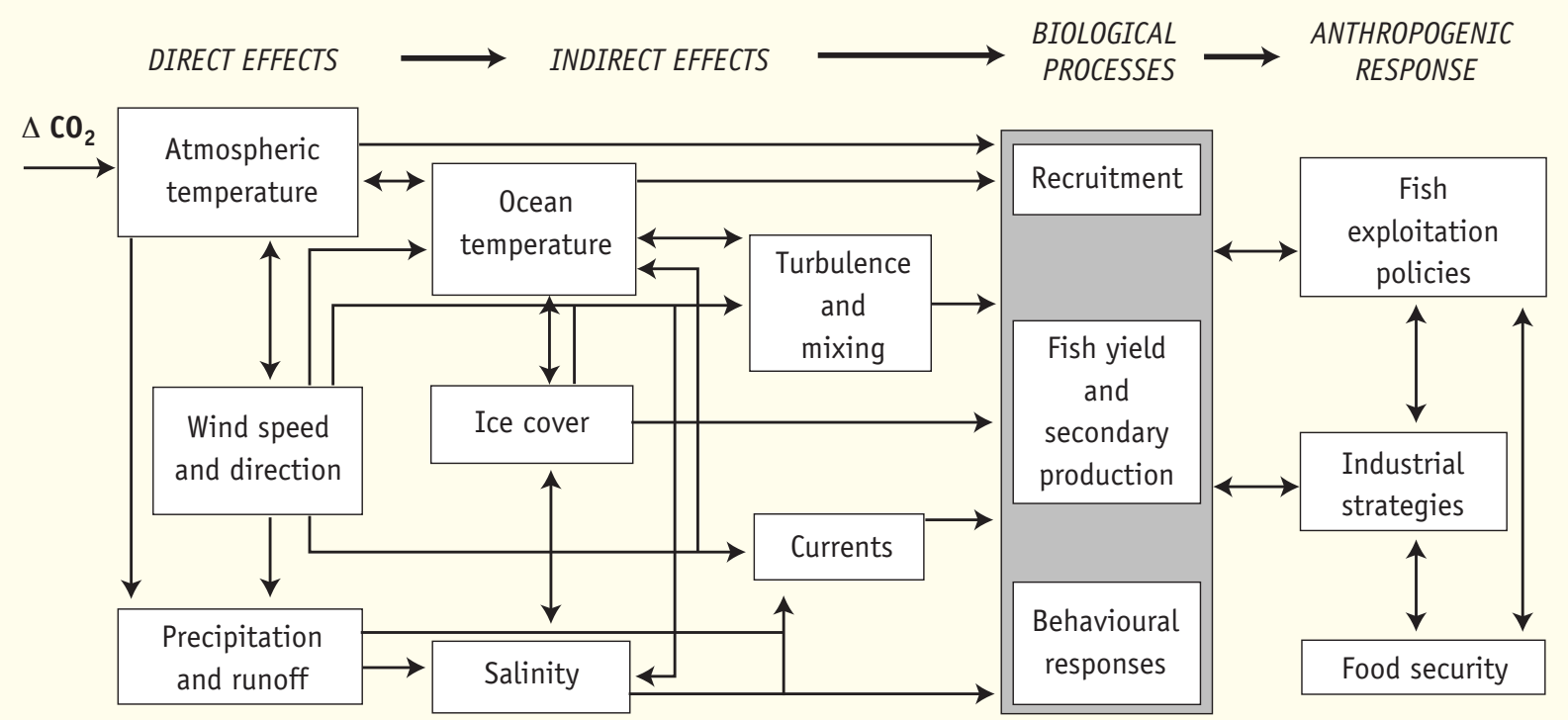

Figure 2 Major pathways through which global change affects marine populations and their exploitation. The shaded area identifies the core objective of GLOBEC.

Source: Adapted from Barange (2001) Issues in Envir. Sci. Technol. 17: 57-82

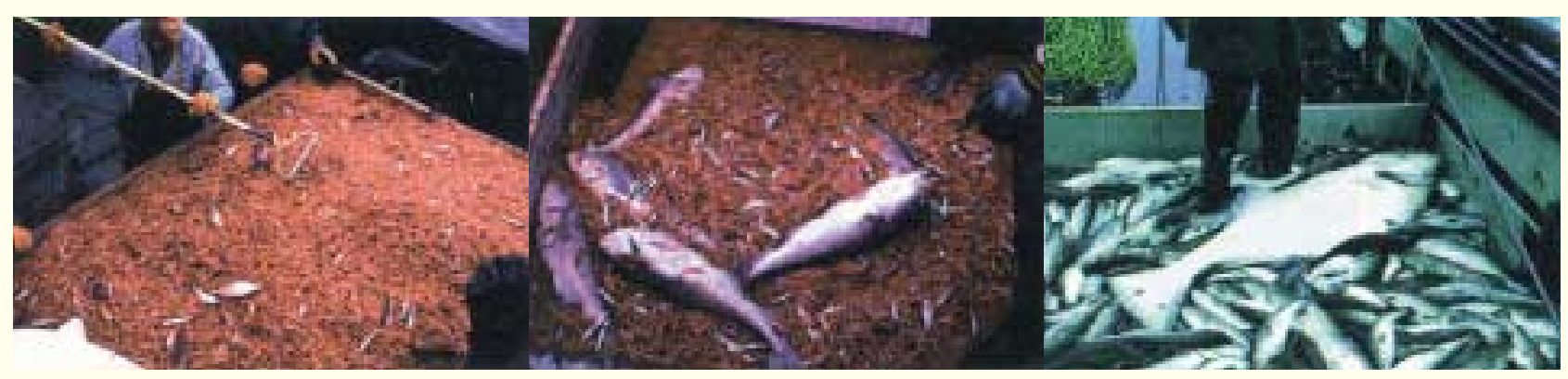

Figure 3 In the mid-1970s there were large changes in species dominance in sea bed communities off Alaska. This 'regime shift' is reflected in the changed composition of trawl catches, from shrimp- (left) to fish- (right) dominated, in Pavlof Bay (Alaska). Source: Botsford et al. (1997) Nature 277: 509-515 

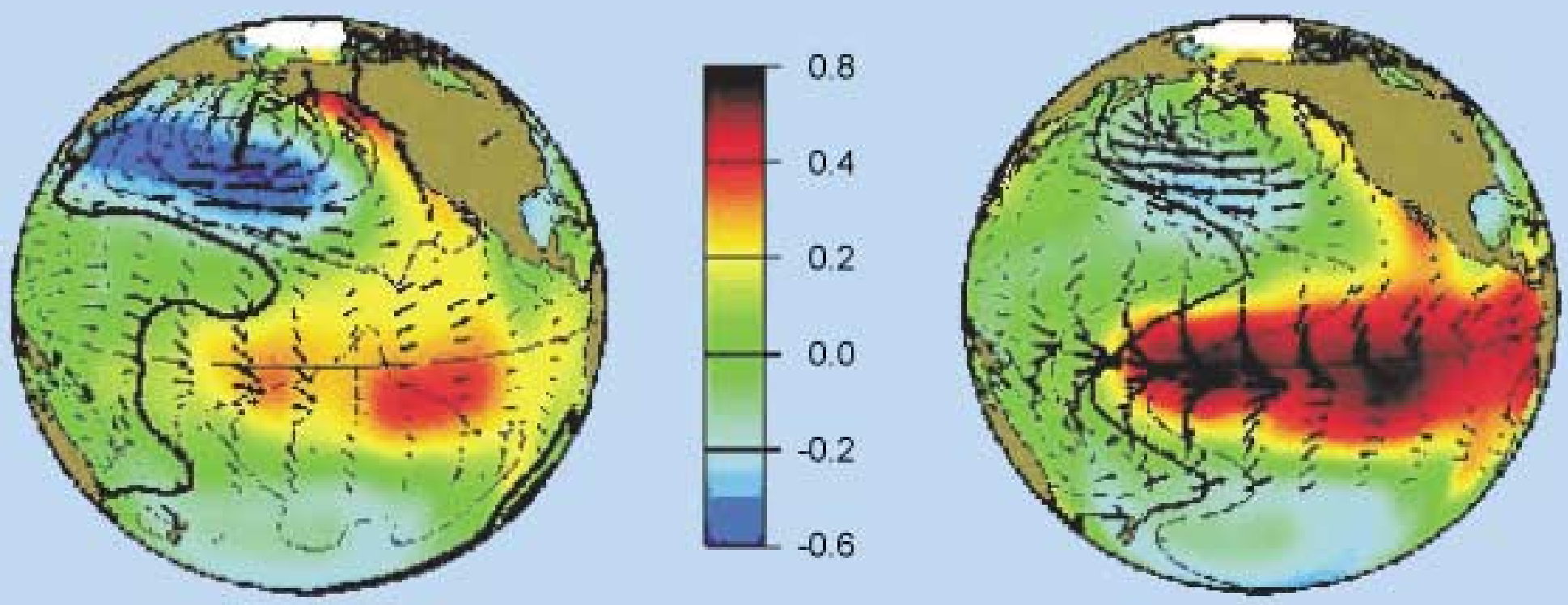

\title{
Global Processes
}

\section{Impacting the Oceans}

\author{
Human influence and physical forcing affect both climate \\ variability and climate change. Distinguishing change (trends) \\ from natural variability (range) enhances the ability to project \\ future patterns of climate change.
}

Spatial maps of the Sea Surface Temperature anomalies in the Pacific Ocean associated with the Pacific Decadal Oscillation and El Niño Southern Oscillation events. The basin-scale physical processes that generate these patterns also organise large-scale patterns of biological variations. Source: Manua et al. (1997) Bull. Am. Meteor. Soc., 78, 1069-1079

\section{Climate forcing of ocean ecosystems}

Changes in ocean temperature, currents and salinity affect many aspects of the variability of oceanic biological populations. This forcing is particularly obvious on seasonal (and shorter) timescales where variations in sea surface temperature (SST) and upwelling, for example, strongly control productivity, growth and migration of marine organisms.This same forcing is also evident on inter-annual timescales associated with El Niño and La Niña episodes. On longer timescales, we still do not fully understand the mechanisms that cause changes in physical oceanographic conditions to influence ocean biology.

One of GLOBEC's central goals is to better determine how variations in ocean climate affect marine eco- systems. The most important physical oceanographic variables that influence biology are thought to be temperature, the thickness of the surface mixed layer (a wind-mixed warm layer present in all seas), the strength of wind-driven upwelling, upper-ocean currents and the extent of sea ice. Correlations between these variables and long-term changes in ecosystems have routinely been identified but the specific mechanisms involved are usually unclear.There are a number of reasons for this: ecosystems can be simultaneously influenced by many physical variables; they can also be very sensitive to the seasonal timing of the anomalous physical forcing; and ecosystems can generate intrinsic variability on climate timescales. In addition, observations are still 
too limited to elucidate both the physical and biological processes that lie behind these correlations.

It has been suggested that the basin-scale nature of climate change causes patterns of response in the oceanic ecosystem. For example, salmon stocks in Alaska tend to vary in phase with each other but out of phase with northwestern U.S. salmon stocks. Similarly, basin-wide correlations and anticorrelations occur between geographically disparate sardine and anchovy populations.

Climate scientists continue to unravel the physical mechanisms and identify the predictable components of climate variations in the ocean-atmosphere system. For example, Figure 4 shows that SST off the coast of Japan can be predicted with significant accuracy at 13 year lead times. Determining the influence of these subtle and complex physical changes on ecosystem dynamics is a major scientific challenge that GLOBEC is addressing.

In the following sections we introduce examples of climatic impact on marine ecosystems, from the millennial to the seasonal scale, from selected GLOBEC and GLOBEC-related research.

\section{Predicting climate variation in the oceans}

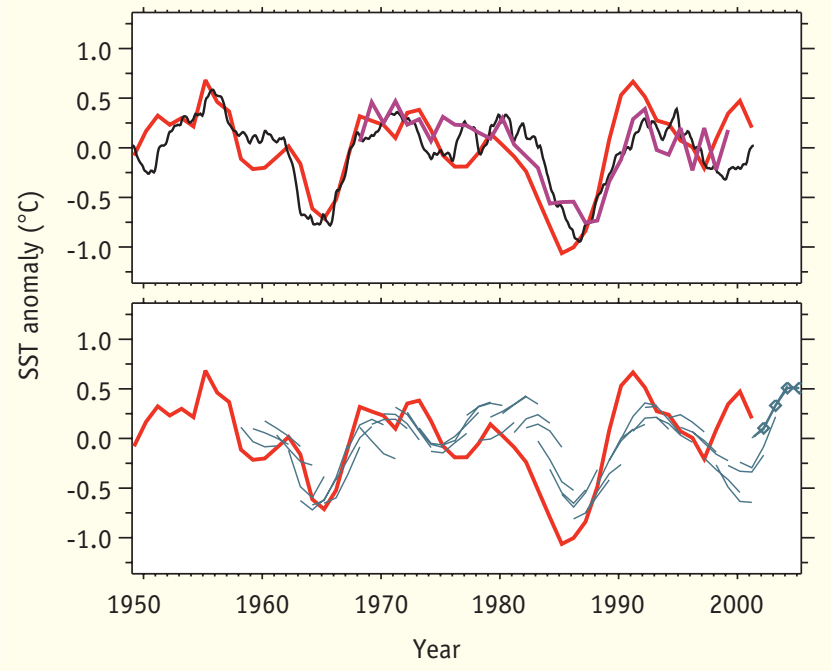

Figure 4 Sea surface temperature (SST) off the coast of Japan can be predicted with reasonable accuracy up to 3 years in advance. The top panel shows observed surface (red) and sub-surface $(100-400 \mathrm{~m})$ (purple) winter SST anomalies for a broad oceanic region off the coast of Japan, where the Kuroshio and Oyashio currents converge and ecosystem productivity is high. This SST pattern can be hindcast with a simple ocean model, driven by observed winds, as shown by the black line. Retrospective forecasts of SST are shown as green lines (bottom panel), and real-time forecasts are highlighted by diamonds for the winters of 2002-2005. Source: Adapted from Schneider and Miller (2001) J. Climate 14: 3997-4002

\section{Millennial to centennial scale variability:} climatic impact on the Bohuslän herring fishery

Historical records can provide evidence of the effect of climate variability on marine ecosystems in the past.The Bohuslän region is a small coastal stretch on the Swedish west coast. As long ago as Viking times, large numbers of herring migrated to the Bohuslän coast to overwinter. These periods of migration to the Bohulän coast lasted 20-50 years and were interrupted by even longer time spans of 50-70 years, when herring migration did not occur. Nine of these 'Bohuslän periods' were recorded due to their impact on the economy of this otherwise farming region (Fig. 5).

The impact of the herring migrating to the Bohuslän coast was such that during the eighth period, for example, up to 50,000 people came annually to the region. During these periods of herring migration the season often prematurely came to an end because the markets could not absorb all the herring. The benefits of the fishery were also noticed when the herring suddenly stopped arriving; the whole economy collapsed and Bohuslän became a poverty-stricken region again.

Was there a correlation with climate variability? The onset of these periods seems to have been triggered by large drops in temperature and their termination usually coincided with temperature increases (Fig. 5). The variability of regional air temperature over northwestern Europe on decadal time scales is controlled by the

\section{Historical records as evidence of climate variability}

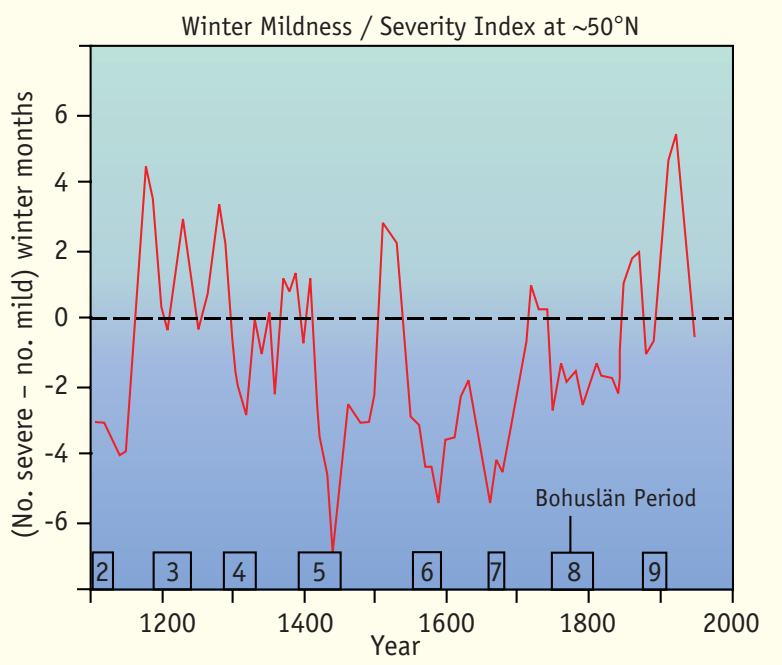

Figure 5 The economy of the Bohuslän area, SW Sweden, has historically been dominated by the abundance of herring. Nine periods of economic prosperity over the last 1000 years are related to periods of cold climate, as indicated by the winter mildness/severity index at $50^{\circ} \mathrm{N}$.

Source: Reprinted with permission from Alheit and Hagen (1997) Fish. Oceanogr. 6: 130-139 
North Atlantic Oscillation (NAO), the difference in air

Year

\begin{tabular}{|l|l|llllll|}
1000 & 1100 & 1200 & 1300 & 1400 & 1500 & 1600 & 1700 \\
\hline
\end{tabular}

Figure 6 Periods of high abundance of European sardines and herrings over the last millennium show fluctuations in phase or out of phase with herring abundance in the Bohuslän region, SW Sweden. Factors influencing these fisheries are evidently at the scale of the North Atlantic basin.

Source: Reprinted with permission from Alheit and Hagen (1997) Fish. Oceanogr. 6: 130-139 pressure between the low pressure zone over Iceland and the high pressure zone over the Azores. A positive NAO index is associated with mild winters over western Europe.A negative NAO index is linked to the inflow of cold Siberian air masses into eastern Europe, resulting in severe winters over Europe. Bohuslän periods were characterised by cold temperatures at mid to high latitudes of the eastern North Atlantic, increased ice cover off Iceland and in the Baltic Sea, and a negative NAO index with reduced westerly winds and cold water in the North Sea, English Channel and the Skagerrak. In spite of a number of hypotheses presented over the last 100 years, the mechanism of how this climatic scenario induces North Sea herring, either directly (e.g., by changes in currents) or indirectly (e.g., by food chain processes), to migrate for longer periods to the Bohuslän coast is not clear. However, the link to climate variability over long time scales is too powerful to ignore.

Interestingly, several other European herring and sardine fisheries show evidence of similar variability either in phase with the Bohuslän periods or in alter-
Varved (annually layered), anoxic sediments, undisturbed by sediment-dwelling animals, are the only window to investigate the dynamics of fish populations and their environment over the last two to three thousand years. These layered sediments are suitable for high-resolution dating, with preserved fish scales revealing a history of fish population dynamics. Unfortunately, such sites are rare and are mainly encountered in upwelling regions or fjords.

In addition to providing high-resolution data on fish population dynamics, analyses of varved sediment can provide information on past ocean temperatures and be used to infer changes in circulation and marine species distributions. Sediments also preserve remains of micro-organisms such as diatoms, foraminifera and radiolarians, which are used to reconstruct food webs and productivity changes. Chemical analyses (organic carbon and nitrogen and their stable isotope ratios) deliver additional information on historical productivity conditions, such as variations in nutrient supplies. Ancient shallow
SSTs are estimated from the alkenone undersaturation. Reconstructed time series of fish scale deposition combined with proxies of other biological, chemical and physical variables provide long histories of how fish have responded to their environment over hundreds to thousands of years.

As a result of GLOBEC-related work, scientists have been able to partially reconstruct the ocean environment of thousands of years ago. Records from the Santa Barbara Basin in the California Current provide a time series of anchovy and sardine abundance extending back to $300 \mathrm{AD}$. Statistical analysis of these data indicates periods of dominance by sardine or anchovy that lasted about 60 years. Clearly, fish populations exhibited drastic fluctuations long before fisheries existed. Ongoing studies of varved sediments in Walvis Bay, Namibia, show that SST varied considerably over the last 1000 years after a relatively steady phase during the preceding 2000 years (Fig. 7). Relative abundances of the major fish populations, determined from fish scale sedimentation records, changed drastically in response to temperature.
Figure 7 Varved sediments from Walvis Bay, off the coast of Namibia show that the SST fluctuated considerably over the last 1000 years, succeeding a relatively steady phase that lasted 2000 years. The relative abundance of fish scales (lower figure) changed in response to SST changes.

Source: courtesy of J. Alheit, K. Emeis and U. Struck

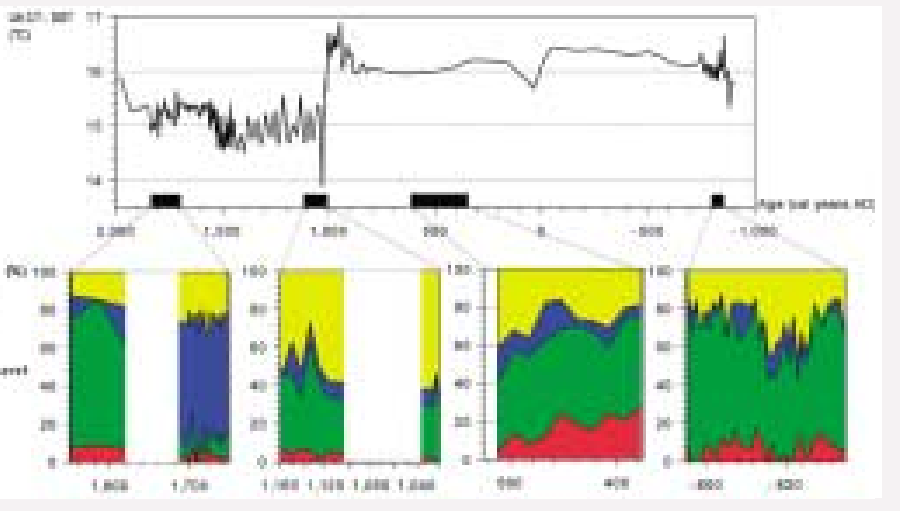




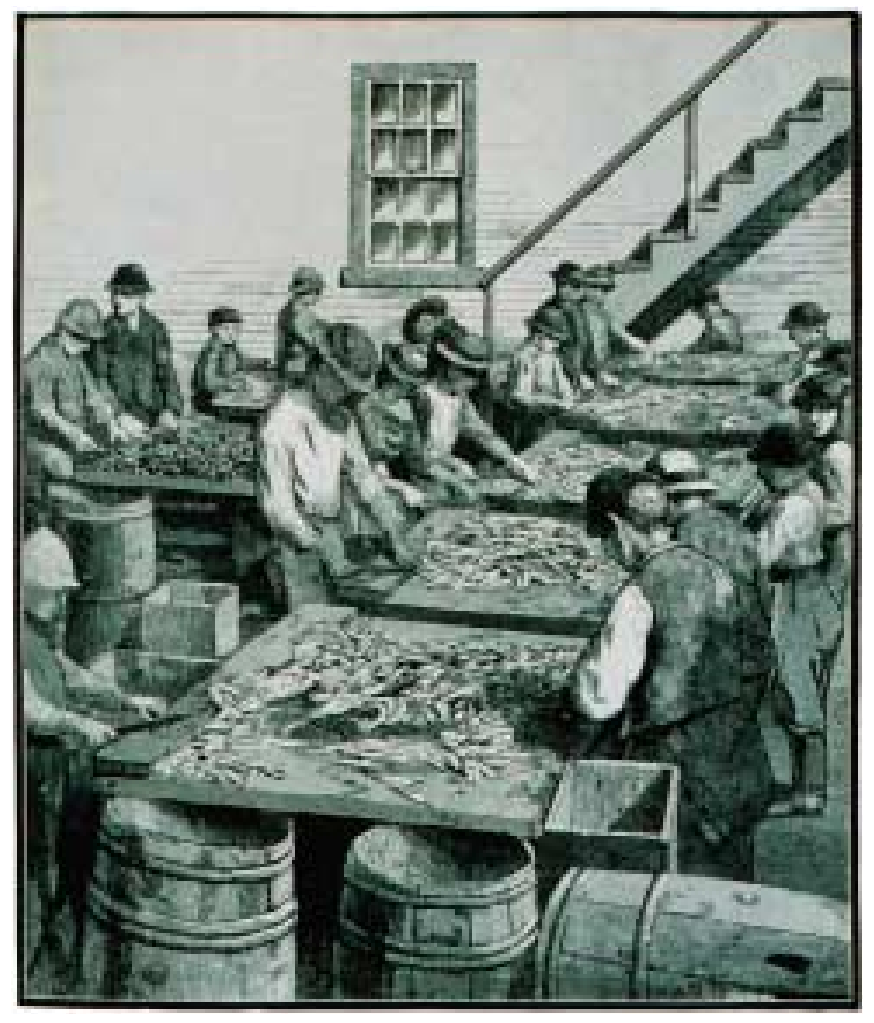

Historical picture of American children canning sardines.

Source: NOAA National Marine Fisheries Service

nation with them (Fig. 6). The fluctuations in European herring and sardine fisheries over the last millennium appear related to temperature regimes and fluctuate on a centennial scale.

Multidecadal scale variability: climate change and long-term fluctuation of commercial fish catches

Climatic patterns coincide with marine production patterns at decadal to multidecadal time scales. Global fish catches (largely driven by Atlantic and Pacific catches) appear to have followed cycles of variability of about 55-65 years over the last century. Similarly, reconstructed records of anchovy and sardine abundance off California over the last 1600 years show fluctuations of 50-70 years per cycle.The Atmospheric Circulation Index (ACI) is a measure of the dominant direction of air mass transport over the Northern Hemisphere. Spectral analyses of the $\mathrm{ACI}$ over the last 150 years indicate that the dominant direction of air masses also changed on a cycle of 55-65 years, in agreement with fish cycles.

Global fish catches can be grouped according to whether they vary in phase or out of phase with ACI indices (Fig. 8). The mechanisms by which climate affects the complex processes involved in global fish production are unknown. However, the clue may be the Instantaneous Surplus Production Rate (ISPR), or rate of production per unit of biomass of the species

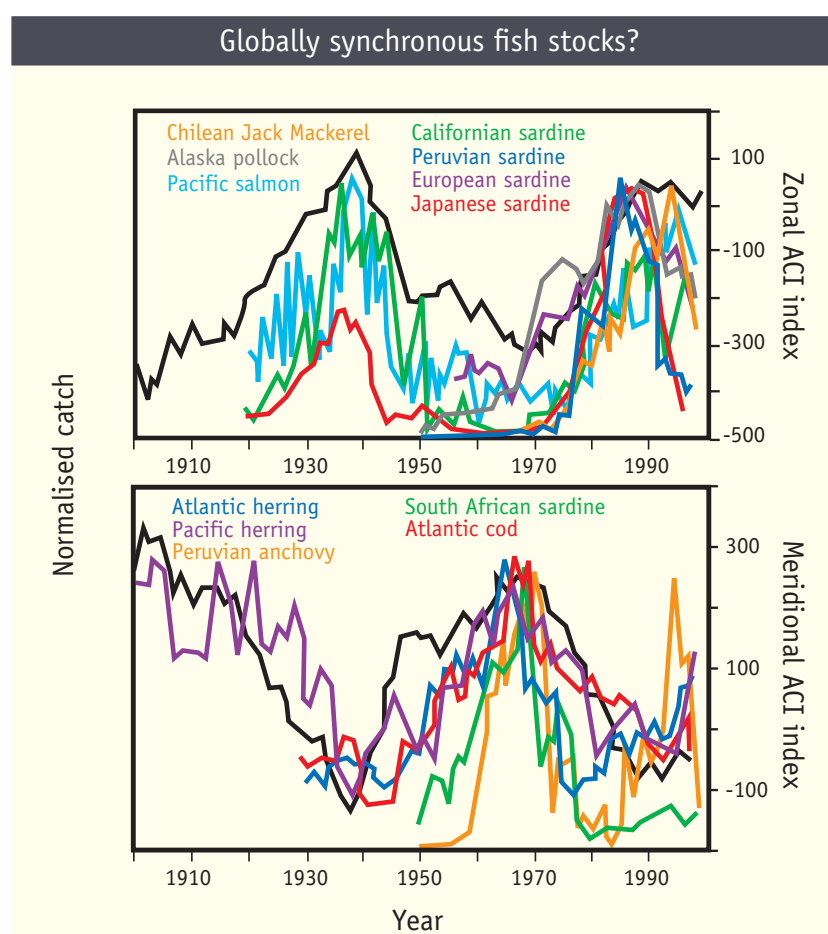

Figure 8 Normalised catches of eleven commercial species of fish (accounting for about $40 \%$ of the world's marine catch) have fluctuated together over the 20th century. Catches also show a strong relationship with the Atmospheric Circulation Index (ACI), a large-scale, multi-decadal climatic index. Zonal and meridional components of the ACI are superimposed on the graphs.

Source: Adapted from Klyashtorin (2001) FAO Fish. Tech. Pap. $410,86 \mathrm{pp}$.

concerned. Periods of high and low production in the ocean ecosystem can trigger massive fluctuations in overall biomass, which may be further compounded by exploitation levels. ISPR could be a useful tool as

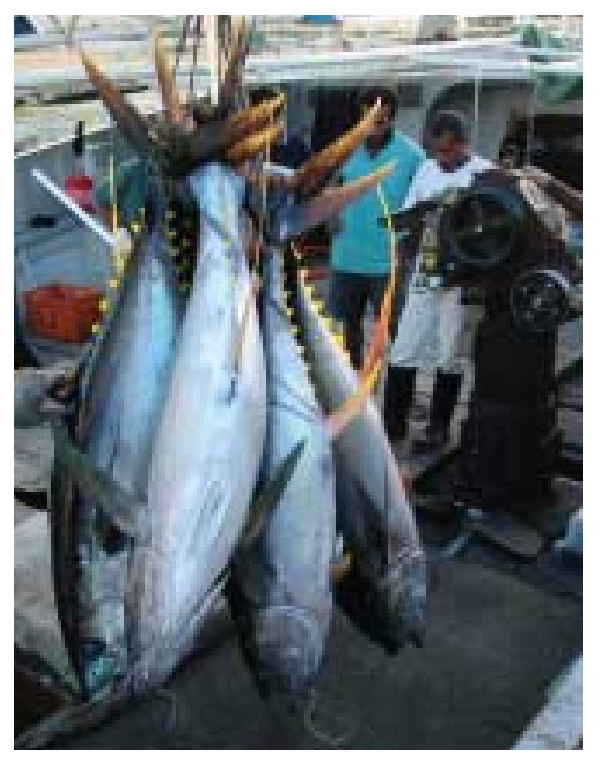

Tuna catches worldwide approach 4 million tonnes per year. Source: Peter Lehodey 
an indicator of global productivity changes and as a mechanism to maximise exploitation levels during high productivity phases while protecting stocks when the ocean is in a low production phase.

\section{Interannual variability:}

\section{El Niño impacts on Pacific tuna stocks}

Tuna are predatory and migratory fish that live in the upper layers of all oceans. In recent years, the annual world catch of the four main tropical tuna species (skipjack, yellowfin, bigeye, albacore) approached 4 million tonnes, with two thirds of the production coming from the Pacific Ocean.

Although most tuna hatch in tropical waters, the distribution of the adult feeding grounds varies among species - some are predominantly tropical in distribution (skipjack, yellowfin), while others migrate to subtropical waters (bigeye, albacore).The El Niño Southern Oscillation (ENSO) appears to have important consequences, both for spatial distribution and migration of tuna populations, and for their level of recruitment and biomass. The predominance of El Niño or La Niña has led to two different regimes.The last El Niño-dominated period (late 1970s to 1998) was characterised by increased catches of skipjack but low catches of albacore. Opposite trends are observed during La Niñadominated years.

A basin-scale, 2-D coupled physical-biological interaction model has been used to explore the underlying mechanisms by which environmental variability affects the pelagic ecosystem and tuna populations, combining a forage (prey) production model with an age-structured population model of tuna (predator). The model is successful in predicting total and spatially disaggregated catch, and in converging estimates of recruitment and biomass with the estimates of population dynamics (Fig. 9). The next step, to be conducted as part of the multinational GLOBEC-OFCCP Project (Oceanic Fisheries and Climate Change) will entail using an input data set calculated from a greenhouse warming scenario to investigate the effects of climate change on this valuable fishery.

\section{Seasonal variability:}

\section{changing seasons in a changing ocean}

At mid-to-high latitudes, the seasonal cycle drives large changes in upper ocean conditions and biological productivity throughout the year. Days are shortest, darkest, and often stormiest in winter; longest, brightest, and often calm in summer. The upper ocean is coldest and least stratified in early spring, warmest and most stratified in early autumn. Inorganic nutrients are often
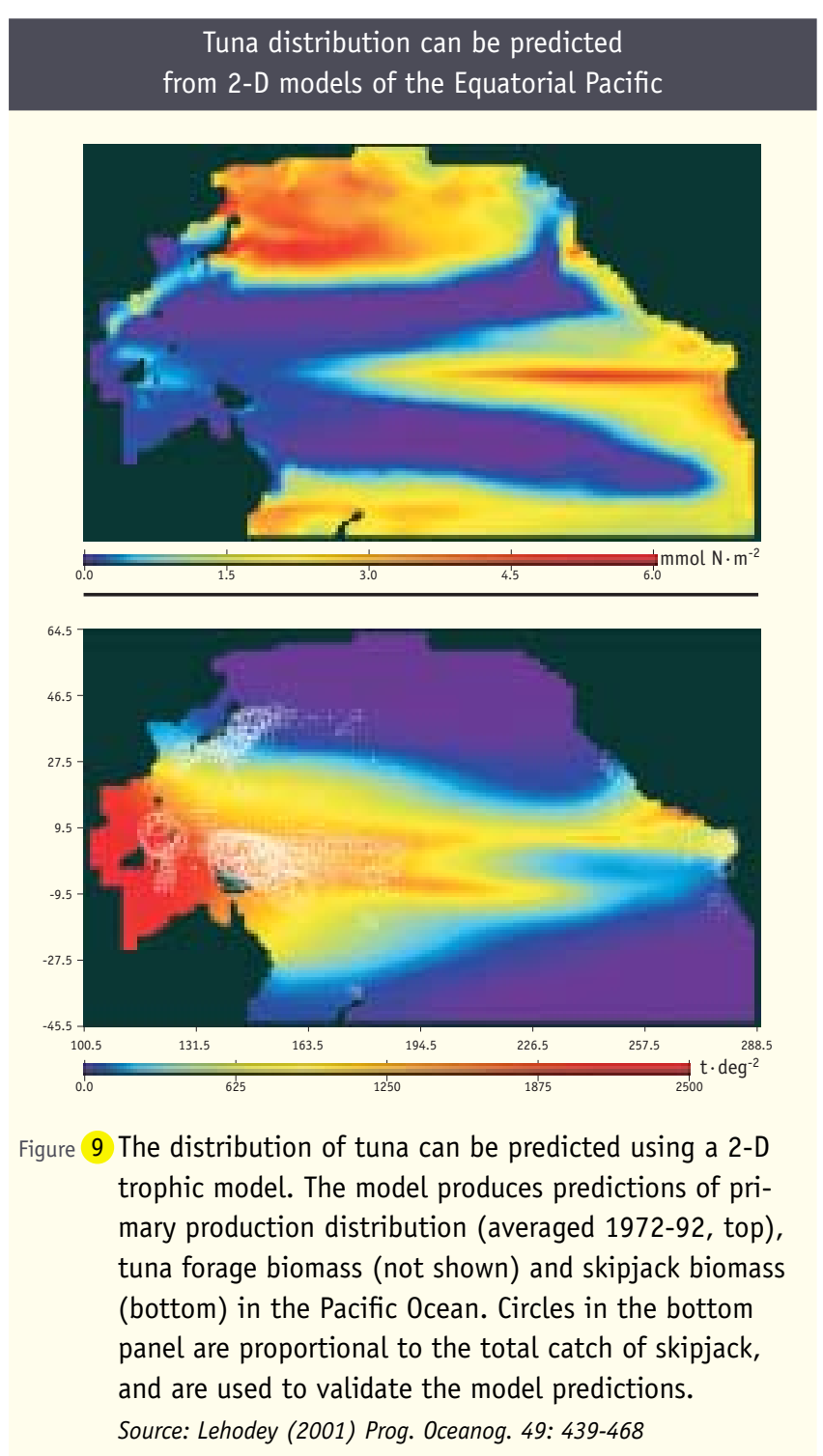

depleted in summer and early autumn. The best growing conditions of the year for most marine organisms are in late spring to early summer, coincident with an annual peak in plankton that occurs while temperature and light are still increasing but before nutrients have become depleted.

Planktonic organisms, in particular, must be welladapted to cope with these cycles; each season is long compared to a typical life span. Many mid- and highlatitude zooplankton species schedule their reproduction, growth and feeding activities to take advantage of an optimal seasonal window. For copepod crustaceans (which make up a large fraction of the total zooplankton biomass), life history adaptations include an annual life cycle, relatively synchronised reproduction and development, and seasonal vertical migration to depths of several hundred metres, followed by dormancy at the over-wintering depth. One consequence of this evolu- 

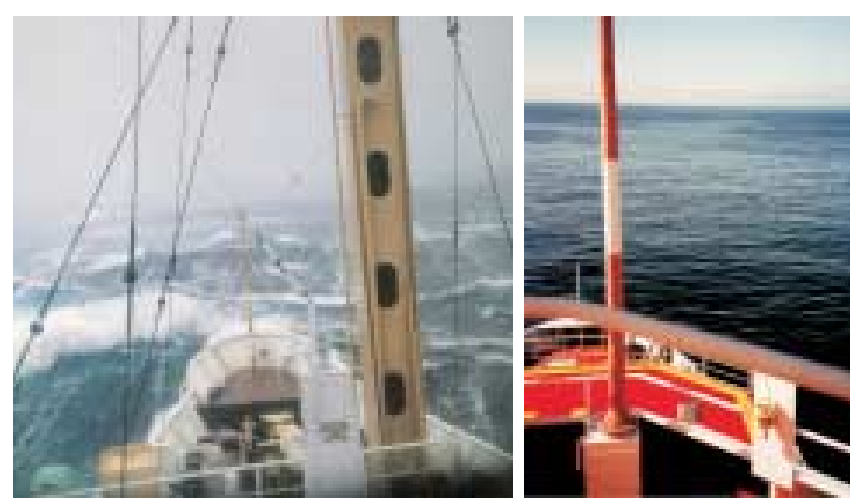

Seasonal cycles cause large annual changes in ocean conditions, particularly in mid to high latitudes. Winter days (left) are short, dim, cold and often stormy. Summer days (right) are long, and sometimes bright and calm. Photos are taken in the subarctic northeastern Pacific.

Sources: Winter picture courtesy of Martha Clemons reproduced with permission from The Oceanography Society. Summer picture courtesy of Fisheries and Oceans, Canada.

tionary adaptation is that the duration of the annual window of high near-surface zooplankton biomass (and peak availability of zooplankton to planktivorous predators) can be very narrow-in the subarctic Pacific, typically only a few weeks.

How might climate change, expressed as changes in the seasonality of ocean physics, affect zooplankton, their prey, and their predators? Evolution selects for adaptations that have worked in the past. Changing environments produce changing ecosystems.

We now know that, at least in the northeastern Pacific, there have been large inter-decadal shifts in the timing, duration and intensity of the productive period.During the 1990s, spring started earlier than it did 20-30 years previ-

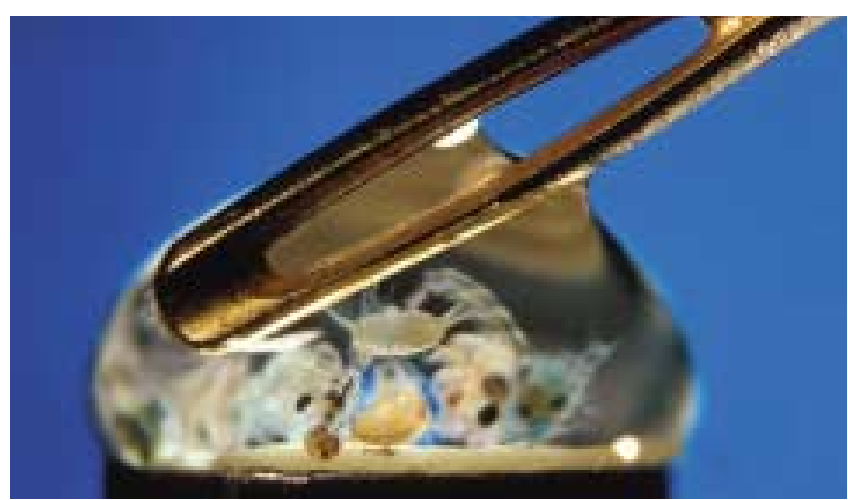

The eye of a needle indicates the size of these tiny zooplankton inside a drop of sea water.

Source: Peter Parks, Image Quest 3-D.

ously (Fig. 10). The surface mixed layer became warmer and shallower, especially in winter and early spring. In some regions, summer nutrient depletion was earlier and more intense. Both in the Alaska Gyre and the Strait of Georgia, the annual zooplankton peak during the mid 1990s occurred at least a month earlier than in the early 1970s. All of these trends have reversed, at least temporarily, following the 1998 La Niña event.These changes in the timing of zooplankton abundance are probably important for the rest of the food web although evidence is preliminary. Planktivorous seabirds are shifting their reproductive effort earlier in the year. Some fish populations are increasing, others are declining, and the direction of change appears to match the time of year they spawn.
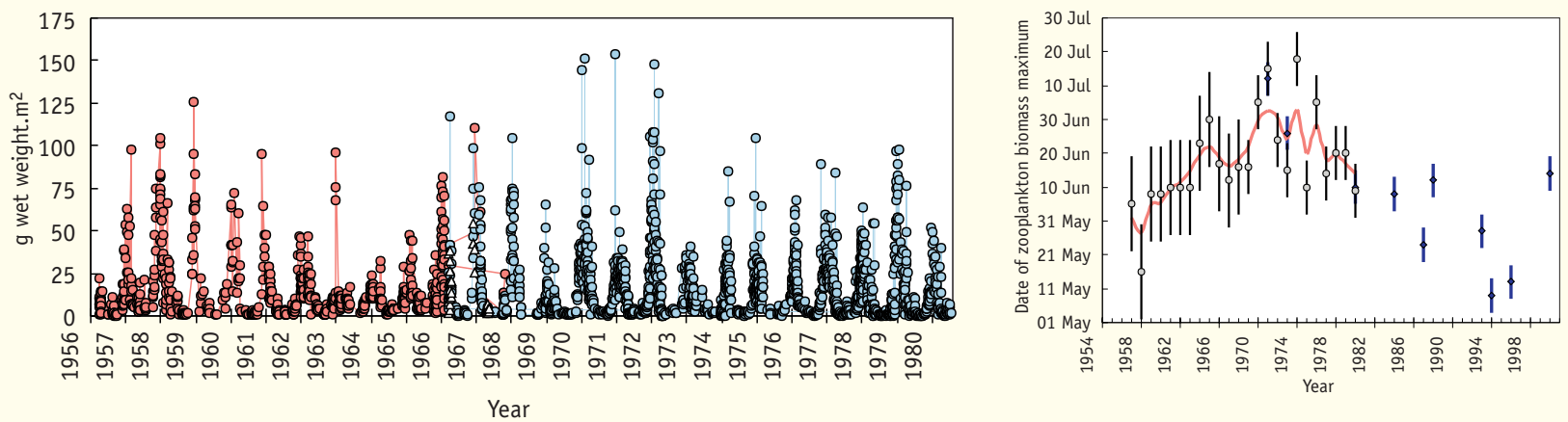

Figure 10 Zooplankton biomass (1956-1981) in the upper $150 \mathrm{~m}$ of the subarctic Pacific $\left(50^{\circ} \mathrm{N} 145^{\circ} \mathrm{W}\right)$ shows a pronounced seasonal cycle (left). The peak of zooplankton production has varied by more than 2 months during the same period (right), following interdecadal shifts in ocean climate. Diamonds indicate dates estimated from developmental stage and composition. Circles are estimates from wet weight biomass.

Source: Adapted from Mackas et al. (1998) Can. J. Fish. Aquat. Sci. 55: 1878-1893 


\section{Introduction of non-indigenous species: Mnemiopsis leidyi in the Black Sea}

Human activity is resulting in global-scale transport and introduction of non-native species into regional ecosystems. The ecosystem effects of such species introductions may be profound, difficult to predict, and may interact with the changing forces acting on ecosystems.

Mnemiopsis leidyi, a gelatinous plankton species, was first reported in the Black Sea in 1982. It is thought that this organism was introduced from the North Atlantic in ships'ballast waters. By the end of the 1980s Mnemiopsis had spread throughout the basin and reached a mass of 1 billion tons. The spread of Mnemiopsis is thought to be a result of high eutrophication, caused by agricultural chemical runoff into the Black Sea, and overfishing.The latter led to the decrease in pressure on forage zooplankton. On entering the Black Sea, Mnemiopsis did not encounter any competitors or predators, and given its high productivity, self-fertilisation and early reproduction (after 7 days) the population grew rapidly. Its increase in the Black Sea was striking; along the Crimean coast Mnemiopsis' abundance increased 4-6 times in less than two weeks. This expansion caused considerable decreases in zooplankton abundance and diversity, and changed the structure of the planktonic community (Fig. 11).

The rapid spread of Mnemiopsis came to an end with the arrival of a new invader, Beroe ovata, which feeds almost exclusively on Mnemiopsis. A sharp

\section{Black Sea trophic links}

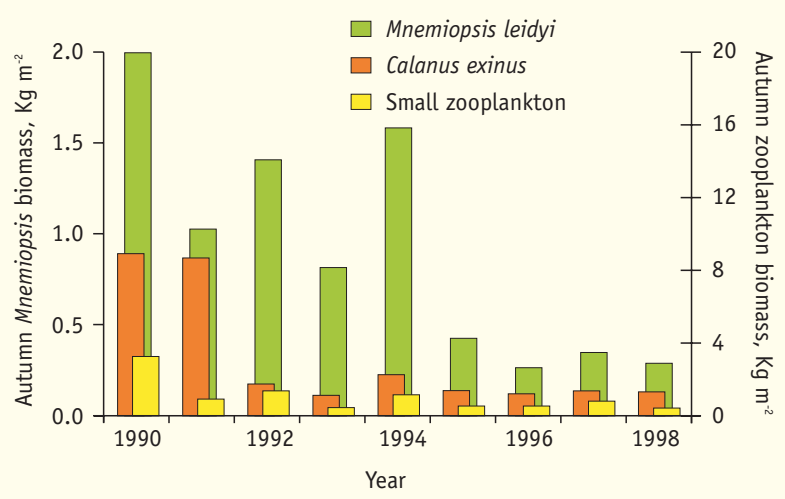

Figure 11 The high abundance of Mnemiopsis leidyi in the Black Sea has led to extreme predation of small zooplankton and excessive competition for food with other zooplankton species, such as Calanus euxinus, both of which show population crashes as a result.

Source: Adapted from Anninsky et al. (1998). In Ivanov \& Oguz (Eds.) Ecosystem modeling as a Management Tool for the Black Sea. Kluwer. pp 249-262

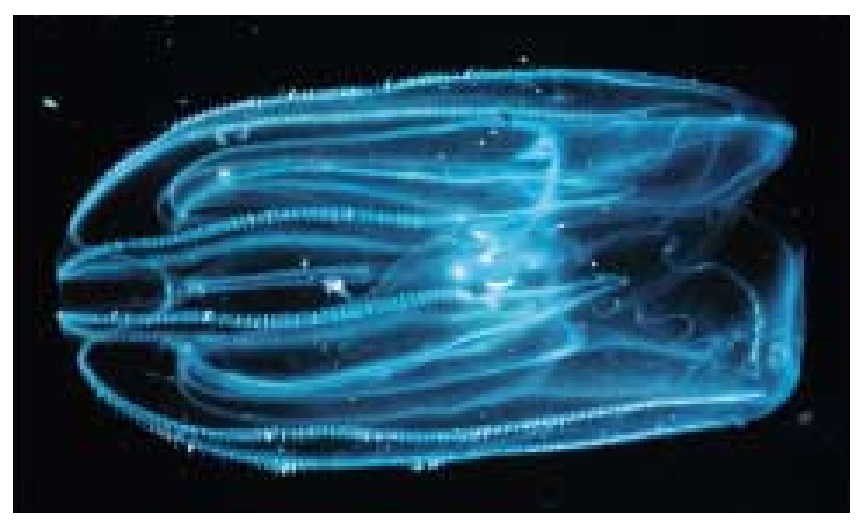

The comb jelly, Mnemiopsis leidyi, an introduced species in the Black and Caspian Seas.

Source: Richard Harbison

decrease of Mnemiopsis biomass, to less than $0.01 \mathrm{~kg} \mathrm{~m}^{-2}$ in 1999-2000, was subsequently observed.Mnemiopsis may have been controlled in the Black Sea, but its effects on the functioning of the ecosystem are longlasting.

\section{Intensive fishing}

After 100 years of rapid geographical expansion and technological advances, marine fisheries are at a crossroads. Annual global harvests increased from 20 to 85 million tonnes between 1950 and 1990, but over the last decade the increase has levelled to almost zero. The industry seems to have reached maximum production, equivalent to about $14 \mathrm{~kg}$ of marine fish per person per year (excluding aquaculture). Little or no growth in marine fisheries production can be expected in the foreseeable future.

The intensive and unrelenting exploitation of the oceans has led to a progressive increase in the proportion of overfished stocks over the last 25 years. In the 1950s most fisheries were undeveloped and very few were overexploited (Fig. 13). Technological developments in gear and fish detection systems, as well as huge investments in the markets, have changed that. Over $50 \%$ of all fish resources are currently either fished at full capacity or overexploited.This points unequivocally towards a state of crisis requiring drastic rationalisation. How will humans adapt to these changes? Nearly one billion people, mostly in Asia, rely on fish for at least $30 \%$ of their animal protein. Globally, marine products contribute about $16 \%$ of human protein consumption.

Society is not only questioning the sustainability of current fishing practices, but also the consequences of these practices for the ecology of exploited ecosystems. Fisheries have become a major player in changing the functional dynamics of marine ecosystems, in the same way that agriculture has changed terrestrial eco- 
A strong linkage to climate and close coupling between trophic levels led to the Southern Ocean being chosen as one of the first regional study sites for GLOBEC. The primary objective of Southern Ocean GLOBEC (SO GLOBEC) is to understand the physical and biological factors that affect growth, reproduction, recruitment, and survivorship of Antarctic species throughout the year. A major focus is to determine the overwintering habitat and to examine the

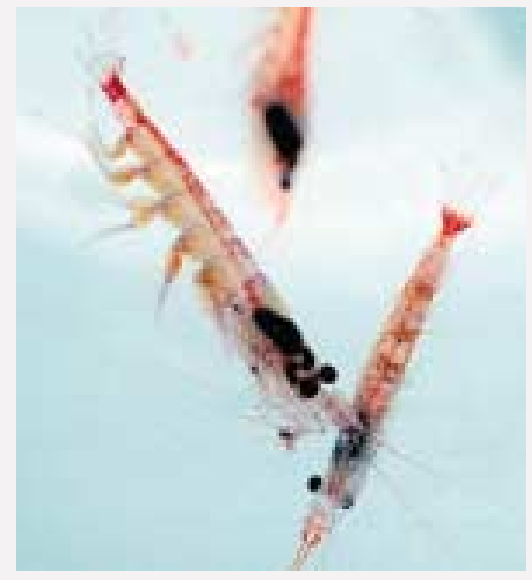

Antarctic krill (Euphausia superba), a central species in Antarctic ecosystems.

Source: Steve Nicol. video recordings, group size verification, behaviour and habitat use observations, and take animal fitness samples. These observations are concurrent with observations of the physical environment, prey distribution and abundance, providing a unique view of baleen whale biology and ecology in Antarctic coastal waters. The emphasis by SO GLOBEC on habitat and predators, as well as krill, is a first in international interdisciplinary Antarctic science.

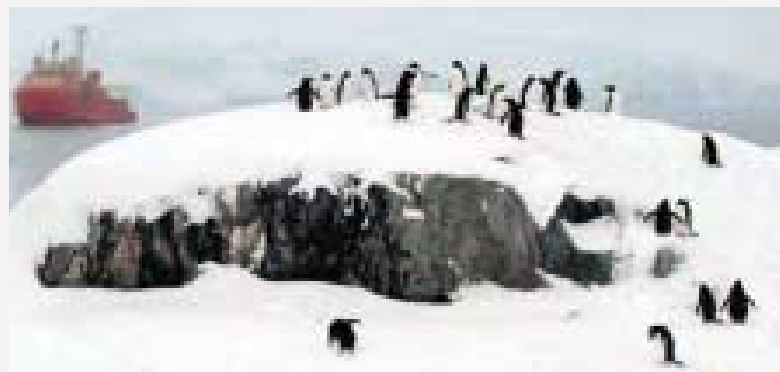

Gentoo penguins, a predator of krill, on Peterman Island along the west Antarctic Peninsula. The ARSV Laurence M. Gould is in the background.

Source: Carey Kuhn.

The SO GLOBEC field programme involves multidisciplinary oceanographic research cruises focused near $70^{\circ} \mathrm{E}$, in the southeastern Weddell Sea, and in the continental shelf waters along the western Antarctic Peninsula. To date there have been about fifteen cruises conducted by Australia, Germany, UK and the USA. Additional SO GLOBEC cruises are planned for the Lazarev Sea by the German Antarctic program. Also, as part of the US SO GLOBEC program, current meter arrays were deployed in the continental shelf waters of the western Antarctic Peninsula to provide the first long-term measurements of the current structure in Antarctic coastal waters.

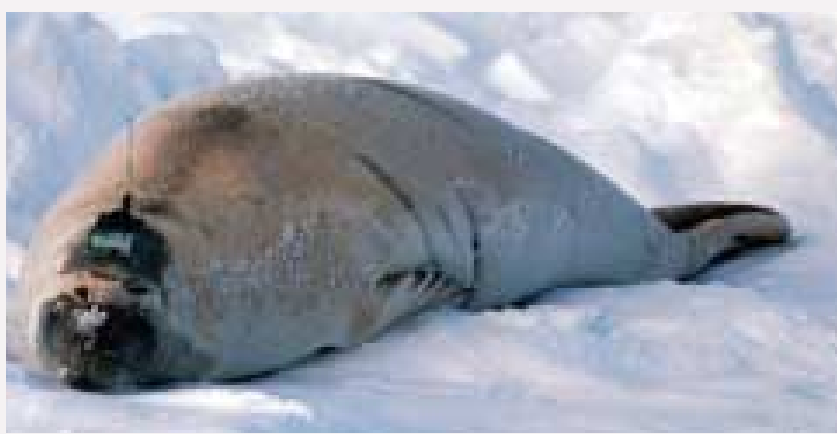

Figure 12 a) A sleeping male crabeater seal with a satellite tracking device attached to his head. The satellite tag transmits information on the animal's dive pattern and location.

Source: Dan Costa.

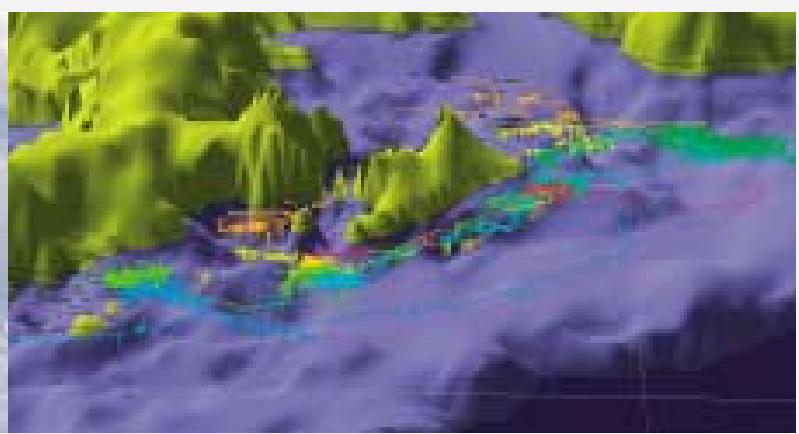

b) Dive tracks of crabeater seals tagged in April-May 2001 presented as a 3-D image. Each colour represents the track of an individual seal. These data are placed in the context of the ocean bathymetry for Marguerite Bay and around Adelaide Island, which are along the west Antarctic Peninsula. Source: Hofman et al. (2002) Oceanography 15(2): 64-74 
Over $50 \%$ of the world's fisheries are overfished
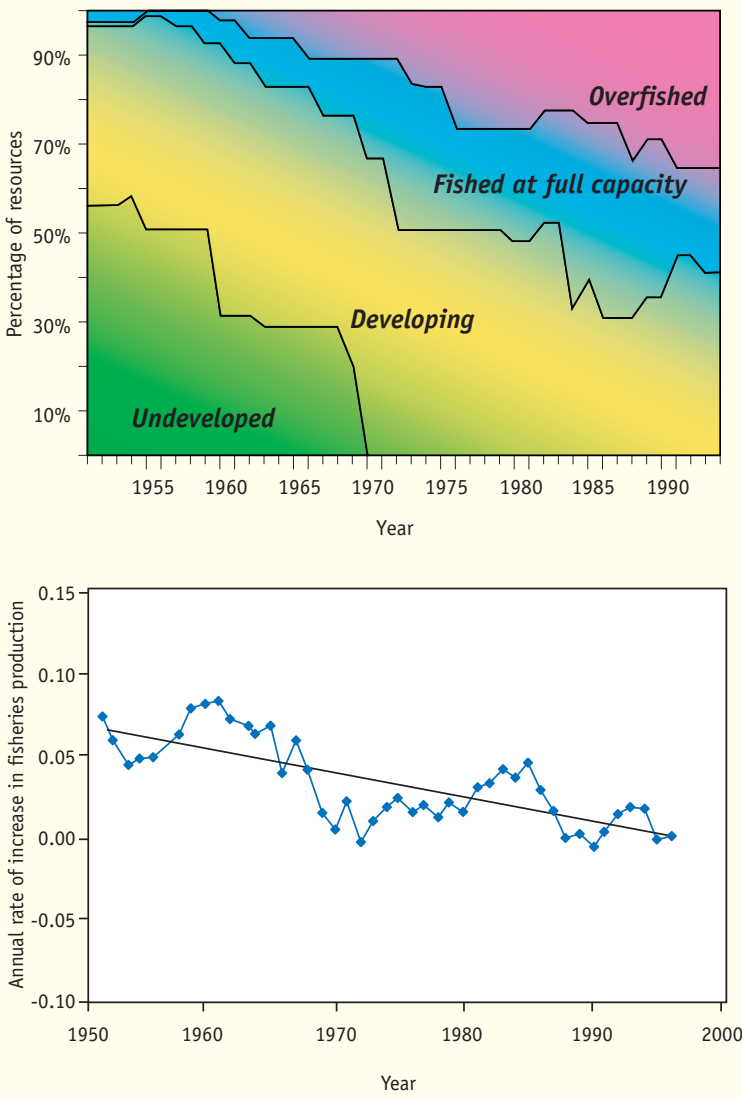

Figure 13 Global trends in marine fisheries show ever increasing proportions of stocks are fished at full capacity or overfished. The top graph shows the percentage of resources by exploitation phase, while below is the annual rate of increase in fisheries production. Source: Adapted from FAO (2000) The State of World Fisheries and Aquaculture, $142 \mathrm{pp}$.

systems. However, the difficulty of obtaining information on whole marine ecosystems means there is little information available on the overall consequences of fishing and overfishing for the exploited communities. This was recognised in October 2001 by the signatory countries of the Reykjavik Declaration, a document on responsible fishing in the marine environment proposed by the Food and Agricultural Organisation of United Nations (FAO).This document states that the countries agree to:

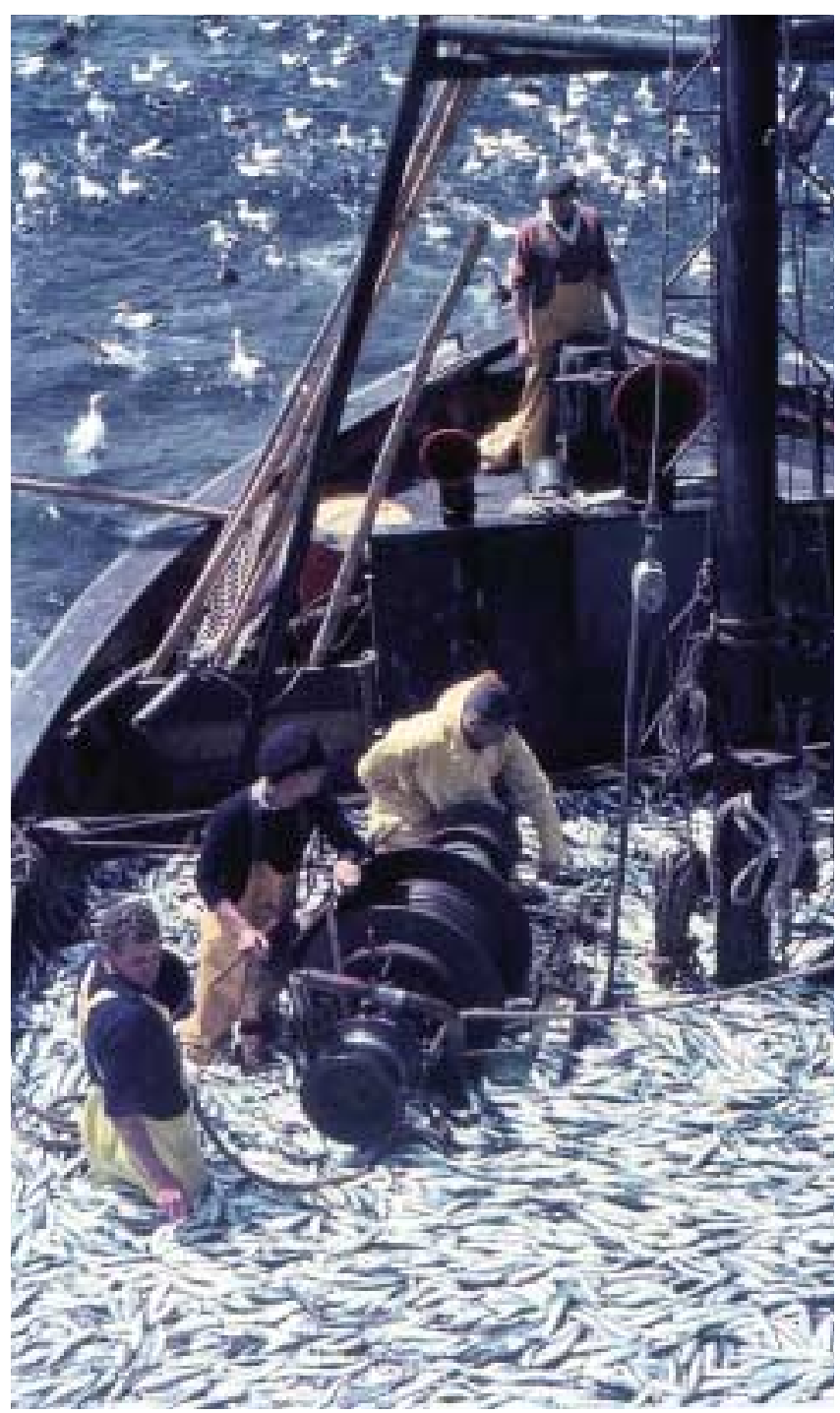

Fishing for sardines off South Africa.

Source: Marine and Coastal Management, Cape Town, South Africa.

...identify and describe the structure, components and functioning of relevant marine ecosystems, diet composition and food webs, species interactions and predator-prey relationships, the role of habitat and the biological, physical and oceanographic factors affecting ecosystem stability and resilience.

Such a pledge further justifies the significant role of GLOBEC in filling these gaps in our knowledge to help manage marine ecosystems. 



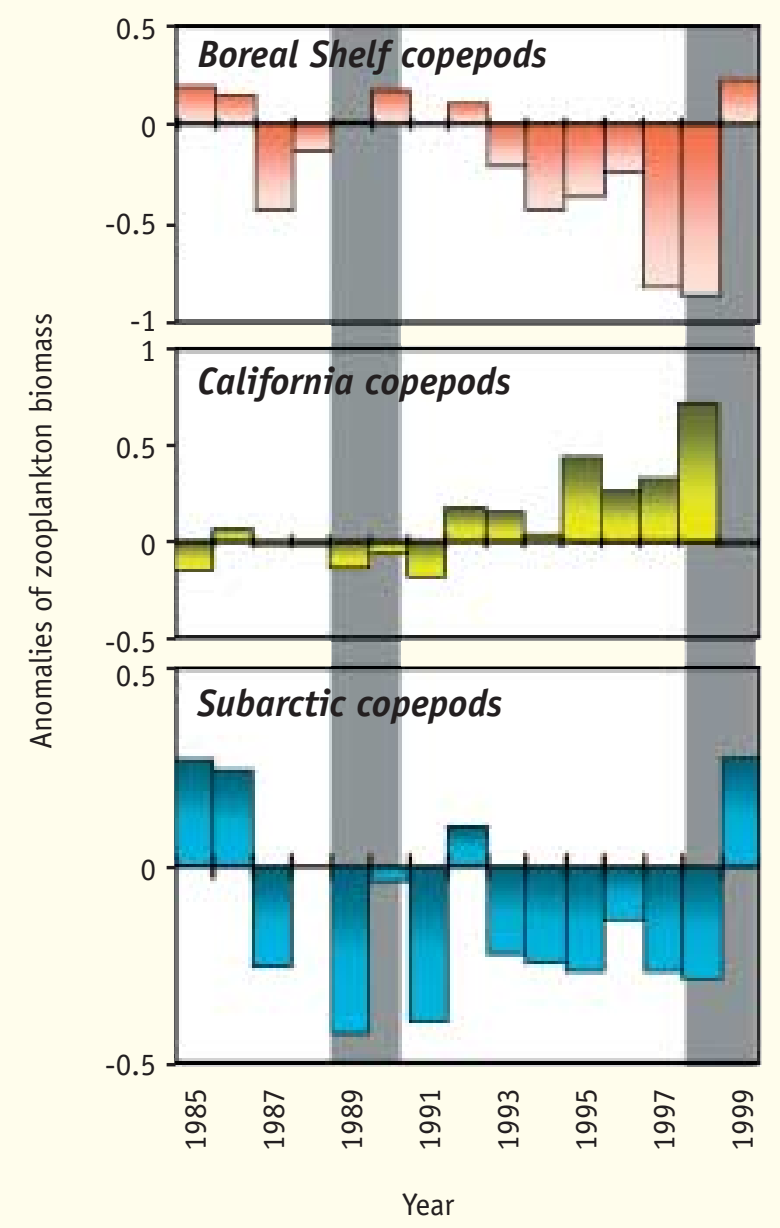

Figure 14 Off the west coast of Canada during the 1990s there was an unusually low biomass of boreal shelf and subarctic copepods, and an unusually high biomass of California copepods. Shading represents periods of greatest change, which are associated with major changes in oceanic conditions, particularly heat content and the balance between poleward and equatorward alongshore transport.

Source: Reprinted with permission from Mackas et al. (2001)

Canadian J. of Fisheries and Aquatic Sci 58: 685-702
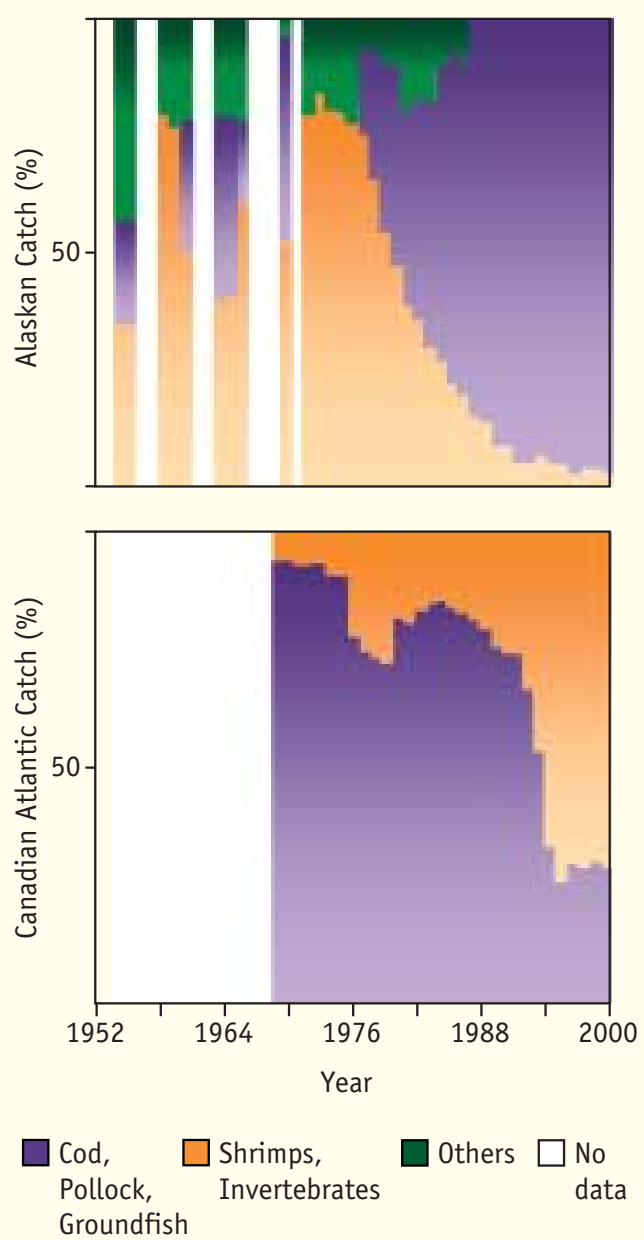

Figure 15 In the Northeast subarctic Pacific, species composition has shifted from crustaceans to groundfish. Opposite changes in species composition occurred about the same time in the Northwest Atlantic, with a shift from groundfish to crustaceans. The causes and consequences of these widespread changes are being considered by GLOBEC.

Sources: Top, reproduced with permission from Anderson and Piatt (1999) Marine Eco Prog Series 189: 117-123. Bottom, courtesy of K. Drinkwater and I. Perry.
Atlantic, but they were opposite to the changes in the Northeast Pacific (Fig. 15). Such changes have affected the structure of these communities, the transport processes responsible for maintaining such structure, the trophic relationships between members of the communities, and the overall functioning of the ecosystem.

One of the roles of GLOBEC is to recognise these changes in structure and functioning, identify the underlying oceanic and atmospheric causes of these changes, and understand their consequences. These can only be fully understood at the level of the individual physicalbiological process, as the overall ecosystem picture may be too complex to interpret as a whole.

\section{Changes in transport processes: migration and survival of the Japanese eel}

In the western equatorial Pacific, at around $15^{\circ} \mathrm{N}$, a 'salinity front' forms where the low salinity water mass in the South meets the high salinity surface water of the North Equatorial Current (NEC). A mysterious long-distance migrating fish, the Japanese eel (Anguilla japonica), 

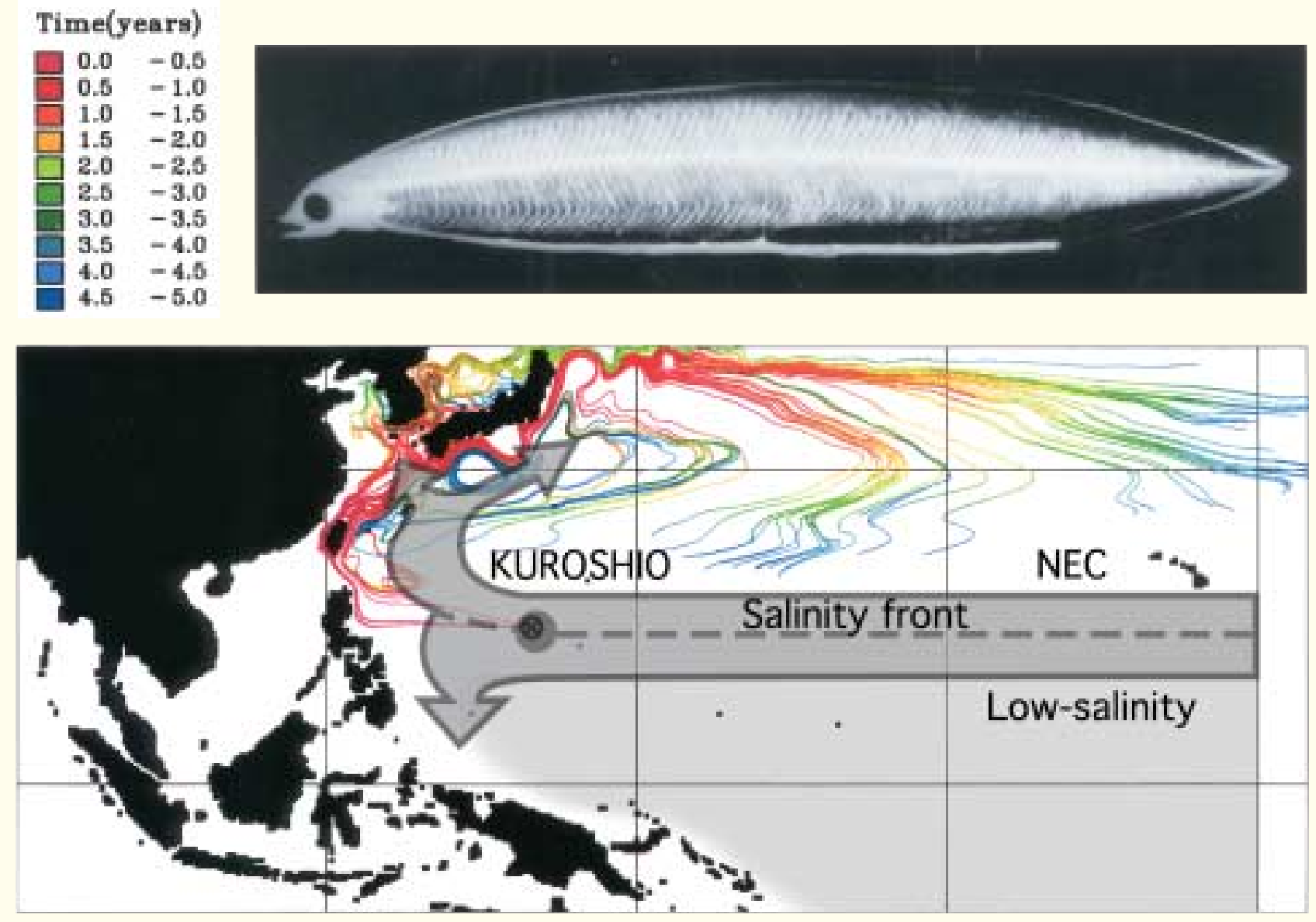

Figure 16 The Japanese eel spawns near the salinity front in the North Equatorial Current (NEC). Larvae (photo) are transported from the salinity front to the inshore nursery grounds. Simulated larval trajectories (coloured lines) suggest that most larvae reach Japan in the first 6 months of life. Climate conditions change the position of the salinity front and can affect the transport and subsequent development of the larvae.

Sources: Top, courtesy of M. Mochioka. Bottom, adapted from Kimura et al. (1999) Marine Ecology Progress Series 186:303-306

spawns its eggs just south of the salinity front. Since this seems to be the only region with appropriate conditions for larval transport, the salinity front in the NEC seems to control the distribution and abundance of the eel in eastern Asian countries (Fig. 16). During the last three decades, larvae abundance has fluctuated strongly from year to year, depending on the strength of El Niño in the area. During El Niño conditions, the salinity front and its spawning grounds are pushed south. Larvae spawned south of $10^{\circ} \mathrm{N}$ lie outside the main circulation loop and are not transported to East Asia, preventing them from contributing to recruitment.

In addition to these fluctuations, there has been a steady overall decrease in larval abundance over the last three decades. Again, the salinity front is a key factor, as it has moved northward gradually during this period, from $13^{\circ} \mathrm{N}$ in the $1970 \mathrm{~s}$ to $17^{\circ} \mathrm{N}$ in the late $1990 \mathrm{~s}$. This means that adult eels now spawn before reaching regions with appropriate current conditions for larval transport, which are located between 10 and $15^{\circ} \mathrm{N}$. Again, larvae cannot reach the nursery ground in time to migrate upstream in rivers. This four degree northward shift of the salinity front is probably the cause of long-term recruitment failure.

Similar decadal scale decreases have occurred in American and European eel recruitment in the Atlantic Ocean.Atlantic-wide ocean climate change, particularly weakness of the Gulf Stream, has been blamed. 


\section{Changes in trophic links: the North Atlantic Calanus-cod story}

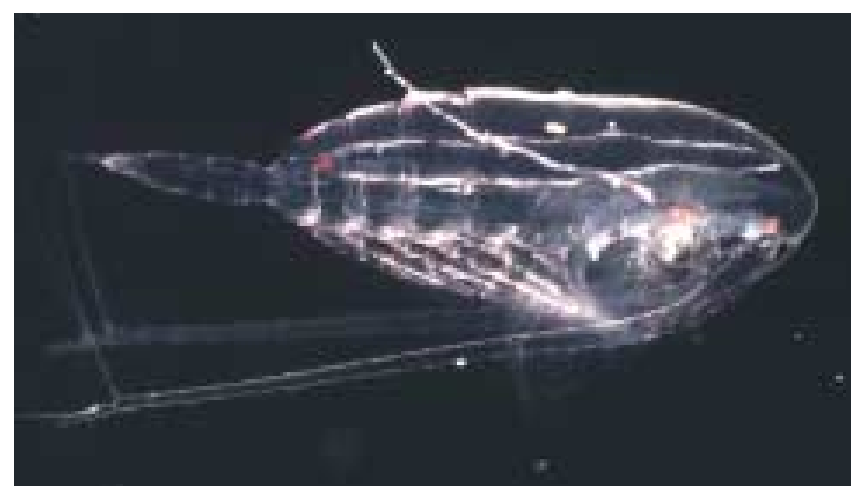

The copepod Calanus finmarchicus is one of the most abundant zooplankton in the NE Atlantic. It is a key species in the ocean food web, being a food source for many fish, including cod. Source: Rger Harris, PML

Over the last four decades, the climate of the North Atlantic Ocean has shifted, as indicated by the North Atlantic Oscillation (NAO) index, which has changed from largely negative to largely positive values.Accompanying this shift were significant changes in ocean surface climate, horizontal oceanic circulation and deep water

The decline of Calanus finmarchicus

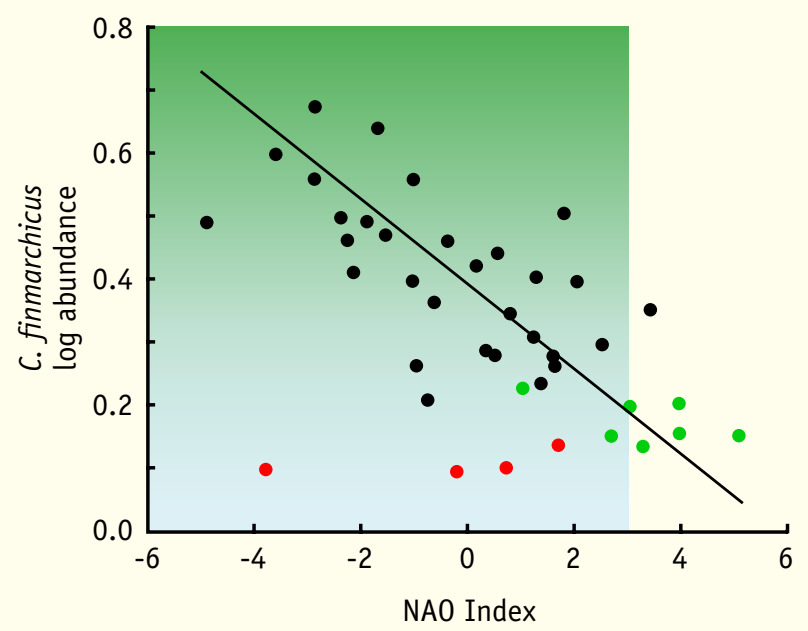

Figure 17 Between 1958 and 1995 (black dots), the abundance of the copepod C.finmarchicus was inversely related to year-to-year fluctuations in the North Atlantic Oscillation (NAO), as indicated by the NAO Index. After 1995 (red dots), the population remained at a low level, independent of the state of the NAO. This shift was probably triggered by a strong reduction in available overwintering habitat (deep cold water off northwestern Europe) caused by altered ocean currents. The time of the shift lies between 1989 and 1995 (green dots).

Source: Adapted from Fromentin and Planque (1996) Marine Ecology Progress Series 134: 111-118 formation. One of the most evident biological changes during this period was the decline in the abundance of the copepod species Calanus finmarchicus in the northeastern Atlantic.This species is a key player in the energy transfer between primary producers and higher trophic levels, including commercial fish species. In the North Sea, the contribution of C. finmarchicus to the annual omnivorous zooplankton biomass declined from $40 \%$ in the mid-1960s to around 5\% today.

The fluctuations in C.finmarchicus abundance in the North Sea were statistically related to the state of the NAO until the relationship broke down in 1996 (Fig. 17). Year-to-year changes in abundance of C. finmarchicus are caused by variations in the transport of animals from their overwintering sites (deep waters off the continental shelf, where they rest in a state of reduced metabolism) to the North Sea. Overwintering habitats, and thus abundance of $C$.finmarchicus, have been reduced over time, as indicated by a reduction in Norwegian Sea Deep Water formation and associated reduced overwintering habitat volume off the western European shelf.

On the opposite side of the North Atlantic basin, decreases in C.finmarchicus abundance appear to be linked to slope water circulation patterns (as indicated by water temperature at $150-200 \mathrm{~m}$ depth), in the Gulf of Maine/Scotian Shelf region, which is also influenced by the NAO. As in the eastern Atlantic, these mechanisms involve changes in local biological processes.

Changes in the abundance and distribution of $C$. finmarchicus have dramatic consequences for its predators, such as juvenile Atlantic cod (Gadus morhua). A combination of water temperature and availability of C. finmarchicus control growth during early stages of the cod lifecycle. Increased temperature enables cod larvae to grow rapidly, but only if there is a sufficient supply of food.The distributions of Atlantic cod stocks do not coincide with the major production regions of $C$. finmarchicus; C.finmarchicus stocks are concentrated in the open ocean, but cod exist around the fringes of those areas on the continental shelf. An increase in advection of water masses from core production regions of C. finmarchicus will improve food availability for early stages of cod while also affecting the water temperature.Arcto-Norwegian cod stocks benefit from the northward movement of warmer, Calanus-rich waters, due to increased growth rates and increased food supply. In contrast, Irish Sea cod would not gain from an increase in water temperature, as this is not accompanied by an increase in food supply. This example highlights the complex translation of physical forcing into biological responses at all levels. 
Cod experience periods of high and low growth and production. In extreme cases, such as some cod stocks on the Canadian shelf during the late 1980 s, low growth rate results in negative surplus production (the amount which can be harvested without diminishing the stock biomass), i.e. the stock declines even in the absence of fishing. Much of the variability in cod growth rate is due to changes in their environment, in particular to temperature and food availability (Fig. 18).

Cod egg development and mortality are also affected by temperature, but the precise mechanisms are still unknown. The ICES-GLOBEC Cod and Climate Change regional programme is developing a sound basis for quantifying the linkages between environmental variables and fish dynamics for use in fisheries management. For example, precise data on growth can now be obtained from counting daily growth rings in fish otoliths (ear bones), providing information on growth rates in early life. It is also now possible to estimate the ambient temperature that the fish experience, using microsampling of the otoliths for oxygen isotope determination.

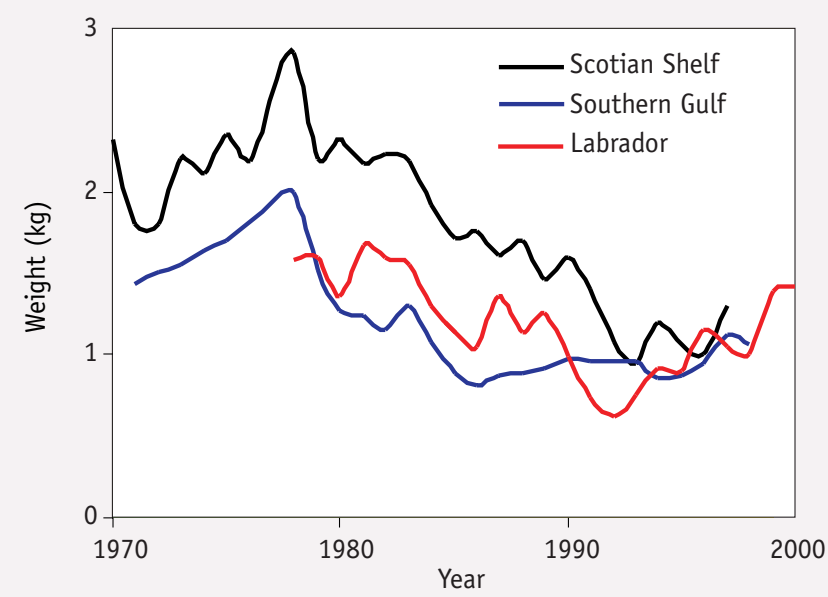

Figure 18 Fish weight at a given age in the 1990s was half that of the 1970s for three Canadian cod stocks. The slowed growth rate is believed to be due to changes in temperature and food availability.

Source: Data courtesy of ICES-GLOBEC CCC working group,

http://www.ices.dk/globec/data/growth/codtabl.htm

\section{Changes in top predator dynamics: North Pacific salmon}

Few oceanographic research projects attempt to look at the whole ecosystem supporting the life cycle of a specific species, from the physical system to the top predators. The Northeast Pacific GLOBEC project tries to understand the dynamics of salmon species, following this ecosystem approach. Records of salmon catch from the North Pacific Ocean suggest that the biological productivity of these ecosystems alternate with characteristic periods of both three to seven years (the El Niño-La Niña cycle) and several decades. The intriguing aspect of these fluctuations is that salmon off Alaska are abun-
The collapse of the cod fishery in the NW Atlantic When the pressure of overfishing coincides with unfavourable environmental conditions, fishery health can quickly degenerate. This was the case in the collapse of the Northwest Atlantic cod fishery. Cod landings in Newfoundland increased markedly from the mid-1800s to reach 150,000 tonnes per year in the 1940 s. By 1968, the northern cod catch reached a maximum of 810,000 tonnes total landings.

Although cod catch was increasing throughout the 1960s, cod biomass had declined 82\% between 1962 and 1977, with the reproductive portion of the stock reduced by $94 \%$. In 1977 Canada extended her boundaries to 200 miles offshore, and increased her own fishing effort considerably. Around 1987, commercial catches began to decline. Just four years later the fisheries for cod and Greenland halibut collapsed inshore, as did total groundfish biomass, and have yet to recover.
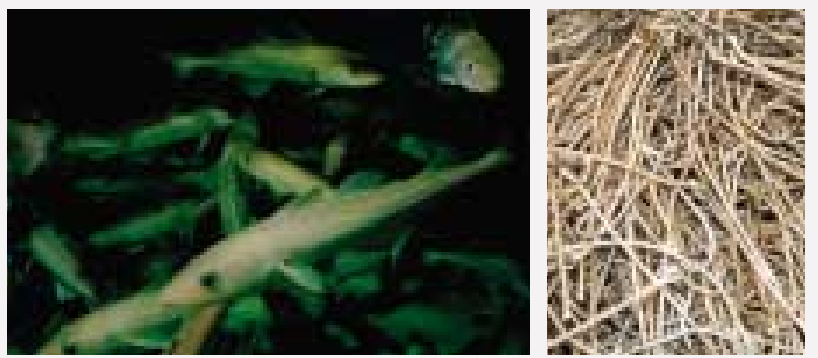

The Atlantic cod and the hooks and longlines used in the cod fishery.

Sources: J.D. Dutil and M. Barange

The collapse has been blamed on many factors, including global climate change. As is usually the case, the causes of the collapse are complex, involving political, social, economic and physical factors.

dant when salmon off the northwest coast of America (Pacific Northwest - PNW) are scarce (Fig. 19).

Despite this general inverse phasing of salmon abundance (all stocks combined) in the PNW and Alaska regions, recent reanalysis by US GLOBEC indicates that responses are species specific, with some species responding strongly to large-scale changes in the marine climate while others remained nearly constant. The responses of the various salmon species to climate variability are therefore more complex than previously thought.

To tackle this problem the US GLOBEC research team is currently investigating how changes in the 
Figure 19 Surface currents in the Northeast Pacific (NEP). In this region, the eastward flowing North Pacific Current splits as it nears the coast and feeds water into both the counterclockwise Alaska Gyre and the equatorward California Current. Large scale changes in ocean conditions mean commercial catches of salmon species off Alaska (blue) and off California, Oregon and Washington (red) fluctuate with high and low periods of 20-30 years. In addition, salmon catches are greater in Alaska when Pacific North West (PNW) catches are low and vice versa. (Note: commercial salmon fishing has been prohibited off the PNW since 1990).

Source: Strub et al. (2002) Oceanography 15(2): 30-35



\section{Climate variability affects coastal productivity}

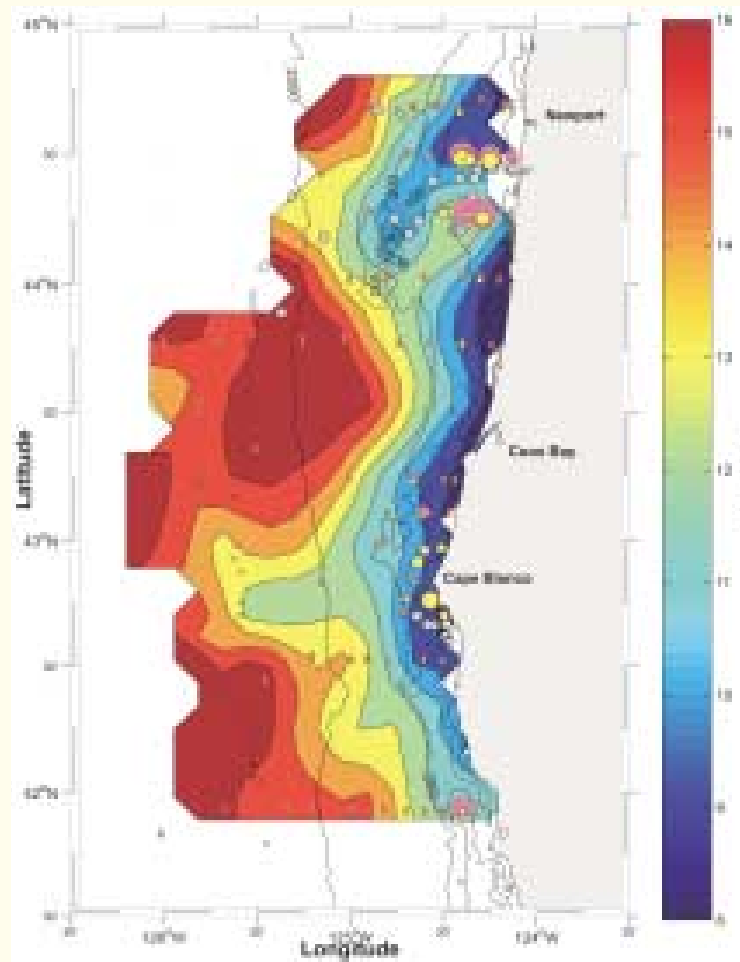

Figure $20 \mathrm{~A}$ combination of both detailed spatial surveys and ecosystem processes gives new insights into how climate variability affects coastal productivity. Above are the results of a mesoscale survey of ocean conditions off Oregon and northern California during August 2000, showing overlapping patterns in the distributions of salmon, their predators (birds, mammals) and prey (copepods). Left Panel. Colour contours show temperature $\left({ }^{\circ} \mathrm{C}\right)$ at $5 \mathrm{~m}$ depth. Yellow and magenta circles are abundances of juvenile chinook and coho salmon, respectively. The largest circles represent catches of ca. 10 fish per standard trawl. Smallest symbols (offshore)

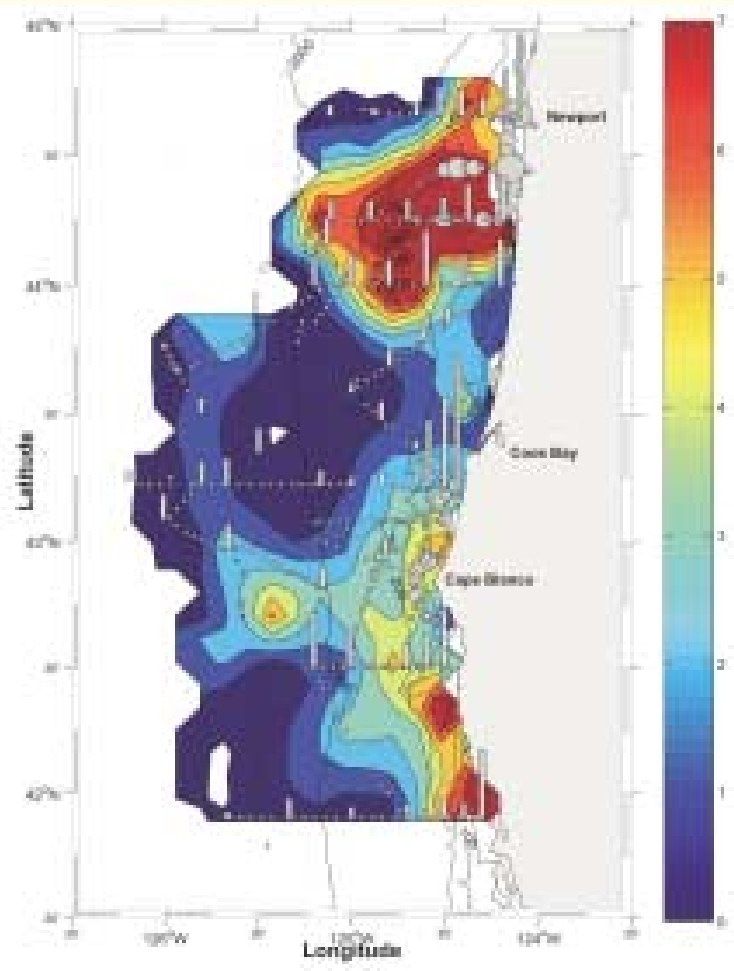

represent trawls in which salmon were not found. The grey circles represent sightings of humpback whales. Note that juvenile salmon were found over the shelf only, and humpback whales were concentrated on Heceta Bank and near Cape Blanco. Right Panel. Colour contoured chlorophyll concentration ( $\mathrm{mg} \mathrm{m}^{-3}$ ) at $5 \mathrm{~m}$ depth. Grey circles depict bird biomass. Bars indicate total copepod biomass $\left(\mathrm{mg} \mathrm{m}^{-3}\right)$ from vertical plankton tows spanning the upper $100 \mathrm{~m}$ or near bottom (if shallower). Note the concentration of birds and copepod biomass nearshore and on Heceta Bank.

Source: Batchelder et al. (2002) Oceanography 15(2): 36-47 
winds and currents affect the productivity of these coastal ecosystems and the survival of juvenile salmon. Fieldwork emphasises both process-oriented investigations and spatial surveys of juvenile salmon, their predators and their prey (Fig. 20). Activities include a sustained programme to monitor changes in both the Alaskan Gyre and California Current systems, computer models of ocean circulation and ecosystem-fish dynamics, and retrospective studies of longer time series of the ecosystems (currents, nutrients, plankton, fish, birds and mammals). Moorings are used to measure currents, water properties and biology, while satellite sensors are being used to measure surface currents, temperature and plankton distributions to provide the larger-scale context for the field measurements. Analyses of these investigations will clarify why the overall abundance of salmon in the Alaskan and PNW regions fluctuates out of phase.

\section{Changes in ecosystem biodiversity: patterns in northeastern Atlantic zooplankton communities}

The heat content of the oceans has increased over recent decades, but the responses of marine organisms to this change are poorly documented.Theory suggests that cold water species should shrink their distribution and move polewards, while warm water species would expand their habitats according to the warming of the environment. Owing to the Continuous Plankton Recorder survey (see Box 5) this theory can now be tested. By decomposing the diversity of calanoid copepods into species assemblages, scientists have observed large shifts in copepod distributions in the North Atlantic (Fig. 21). Warm-water species have extended their distribution northwards by more than $10^{\circ}$ of latitude, while cold-water species have decreased in number and range.These biogeographic shifts agree with changes in the distribution and phenology of many groups of terrestrial European ecosystems and are related to both the increasing trend in Northern Hemisphere temperatures and the North Atlantic Oscillation index.

\section{Changes in ecosystem structure and dynamics: regime shifts}

Throughout most of the $20^{\text {th }}$ century, marine ecosystems were generally regarded as fundamentally stable entities, with fishing considered the only factor normally capable of upsetting that essential natural stability in a major way. However, by the early 1990 s the conventional view was challenged by the steady accumulation of more extensive time series data. Such series revealed a doubling of chlorophyll (an algal pigment) in the subtropical North

\section{Northeastern Atlantic copepod diversity}

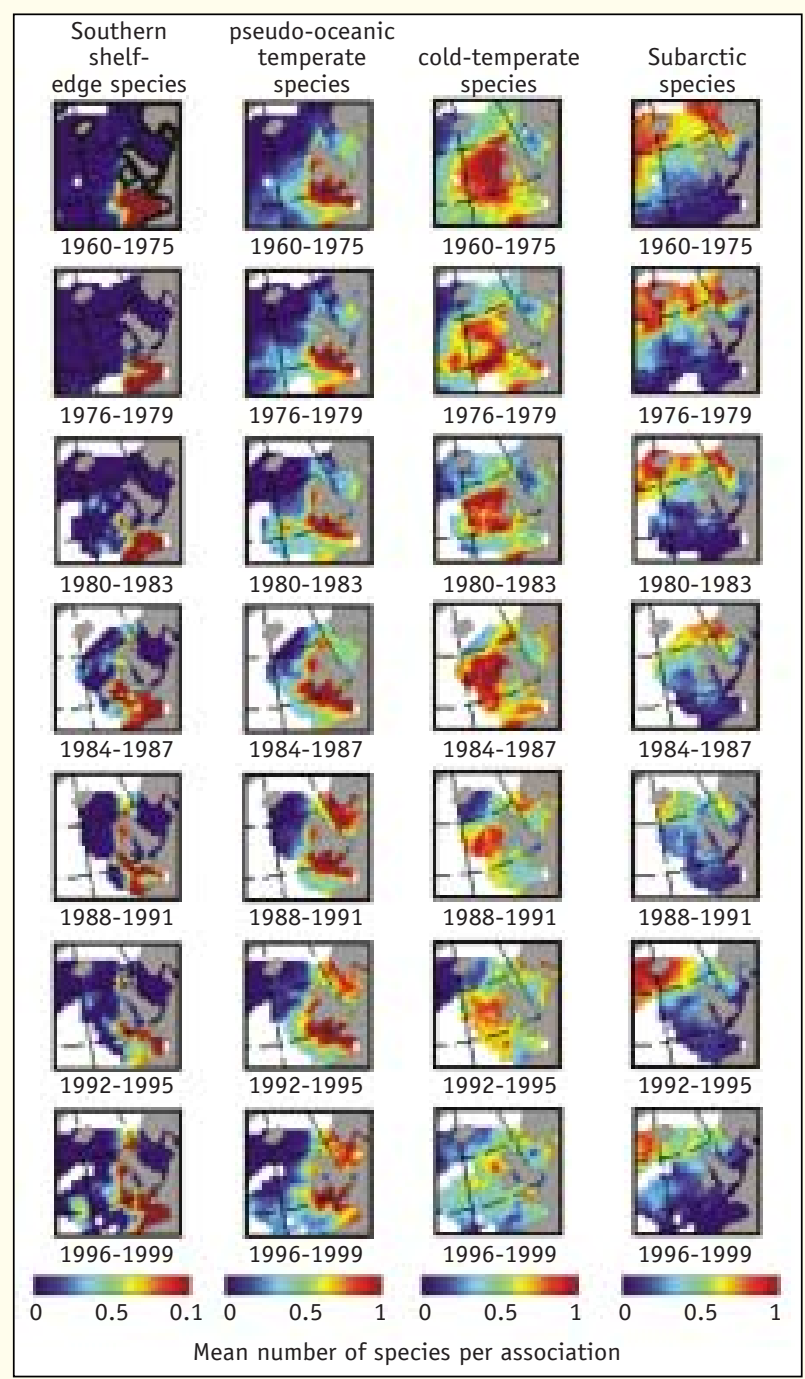

Figure 21 Over the last 40 years, both the distribution and abundance of different copepod species have changed in the northeastern Atlantic. Increasing temperature and changes in the North Atlantic Oscillation are thought to be responsible for a reduction in the habitat of cold temperate and subarctic species, and an increase in the distribution area of southern shelf-edge and pseudo-oceanic temperate species. White areas indicate no data.

Source: Beaugrand et al. (2002) Science 296: 1692-1694 ๑ AAAS.

Pacific beginning in the mid-1970s. There were similar changes in the biomass of zooplankton, pelagic fish and squid in the subarctic North Pacific in the 1980s. On the other hand, since the 1950s zooplankton biomass in the California Current has decreased by $70 \%$, with a corresponding drastic decline in certain seabird species. Peruvian coastal waters also experienced a $60-70 \%$ decline in zooplankton biomass in the mid-1970s, following the collapse of anchoveta populations.

Only when a number of very valuable fish populations (e.g., Atlantic and Pacific cod, Alaskan pollock, 
Japanese sardine, Pacific whiting, chinook and coho salmon), declined dramatically in the late 1980s, did marine scientists finally change their opinion regarding the inherent stability of marine ecosystems. Suddenly, the term "regime shift" was established as a routine part of the vocabulary of marine ecologists and fishery scientists, to describe dramatic and synchronous changes in species composition and abundance, sometimes over widely-separated ocean regions.The distances between these regions were too great for significant population exchanges or other purely biological interactions to occur. Therefore, it seems necessary that some type of very large-scale external forcing was driving these changes, most probably through global-scale climatic teleconnections. For example, the period from the early 1970 s to the mid-1980s was characterised by particularly strong decadal-scale trends in many basin-scale climatic indices (and even in certain global-scale climatic indices, such as globally-averaged air temperatures). In addition, shorter scale variability superimposed on this decadal trend results in particularly rapid step-like changes, as observed in the North Pacific around 1977 (Fig. 22).

These correlations suggest that an extended period of strong unidirectional climatic change, or alternatively an episodic shift to a new quasi-stable dynamic state in the coupled ocean-atmosphere system, might act as a trigger to initiate a succession of interlinked biological events.A more recent, perhaps comparable, regime shift that occurred in the North Pacific region during 199899 is currently being studied. Other possible regime shifts may have occurred around 1945-47, 1970-71,

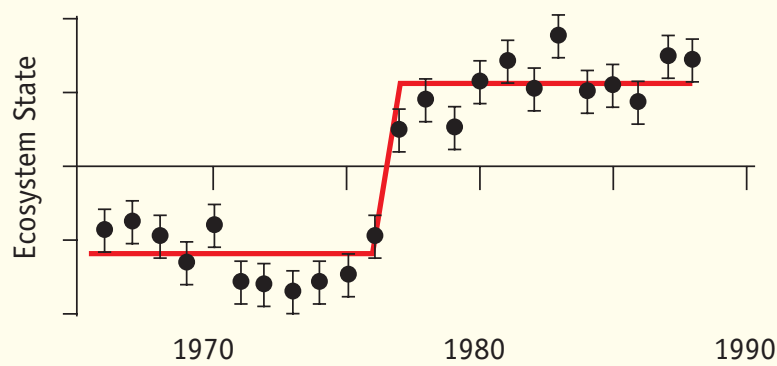

Figure 22 Ecosystems can shift states, triggered by small, often undetected, environmental changes. Such a regime shift occurred in the North Pacific in 1977, caused by subtle changes in the Pacific Decadal Oscillation, and affected zooplankton, shrimp and salmon populations, among others. Note: 'Ecosystem State' is a combined index of 100 biological and environmental variables. Source: Adapted from Hare and Mantua (2000) Progress in Oceanography 47: 103-145

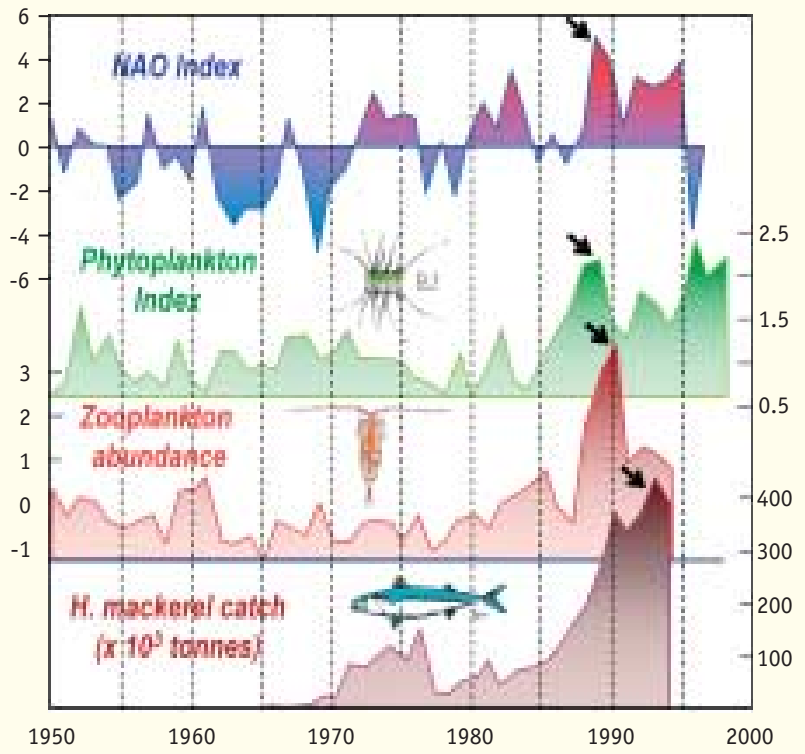

Figure 23 A possible regime shift occurred in the late 1980s in the North Atlantic. A variety of North Sea biological indicators and the NAO Index all changed around that time. Source: Adapted from Holliday and Reid (2001) ICES Journal of Marine Science 58: 270-274; and Reid et al. (2001) Fisheries Research 50: 163-171

and 1988-89. In the late 1980 s, scientists observed dramatic biological changes in the North Sea, coinciding with the highest positive NAO index records for more than a century. Indicators of such a shift are increased phytoplankton and zooplankton abundances and horse mackerel fish catches (Fig. 23). Alterations in the centre of deep water convection from Greenland to the Labrador Sea and increases in the flow of oceanic water into the North Sea through the Shelf Edge Current appear to be the main drivers for such changes.

Marine ecosystem regime shifts are a subject of great current scientific interest in the GLOBEC community. They are also potentially very important in the application of GLOBEC research findings to vital societal issues such as fisheries management and marine biodiversity protection. Research findings will also help to identify anthropogenically-caused trends within the background 'noise' of natural marine ecosystem variability. Regime shifts are proof that while global change effects have to be understood at the level of individual processes and species (as highlighted in some of the previous examples), consequences need to be addressed at the ecosystem level. 
The mechanisms driving regime shifts in the Baltic are strongly linked to the life cycle of cod and sprat, the two main fish species in the region, which alternate in dominance. Time series analysis between the different life stages of cod and sprat suggests that cod's success is linked to mortality at the egg stage, while sprat are more affected by larval mortality. Cod eggs are vulnerable to low salinity and reduced oxygen concentration in the central Baltic Sea, as well as high predation. Sprat recruitment is more dependent on the availability of suitable zooplankton prey, which correlates well with proxies for the NAO index, such as variations in salinity and water temperature. Retention and dispersal from the main spawning ground are also a key process influencing cod larval survival. Due to the large decrease in abundance of the copepod Pseu- docalanus elongatus in the central Baltic Sea during the last two decades, survival of larval cod in that area may now be limited by food availability.

The dynamics of Baltic cod and sprat are intrinsically linked to physical forcing on biological processes, but also to human exploitation. For example, the shift from a cod- to a sprat-dominated system that occurred over the last two decades was caused by both recruitment failure and high fishing intensity on a declining cod stock (Fig. 24). The resulting release in predation pressure on the sprat population led to an exceptionally high sprat stock size. Destabilisation of the system can be caused either by unfavourable hydrographic conditions for reproduction and subsequent recruitment failure of one of the species, or high mortality caused by the fishery.

\section{Regime shift in the Baltic}

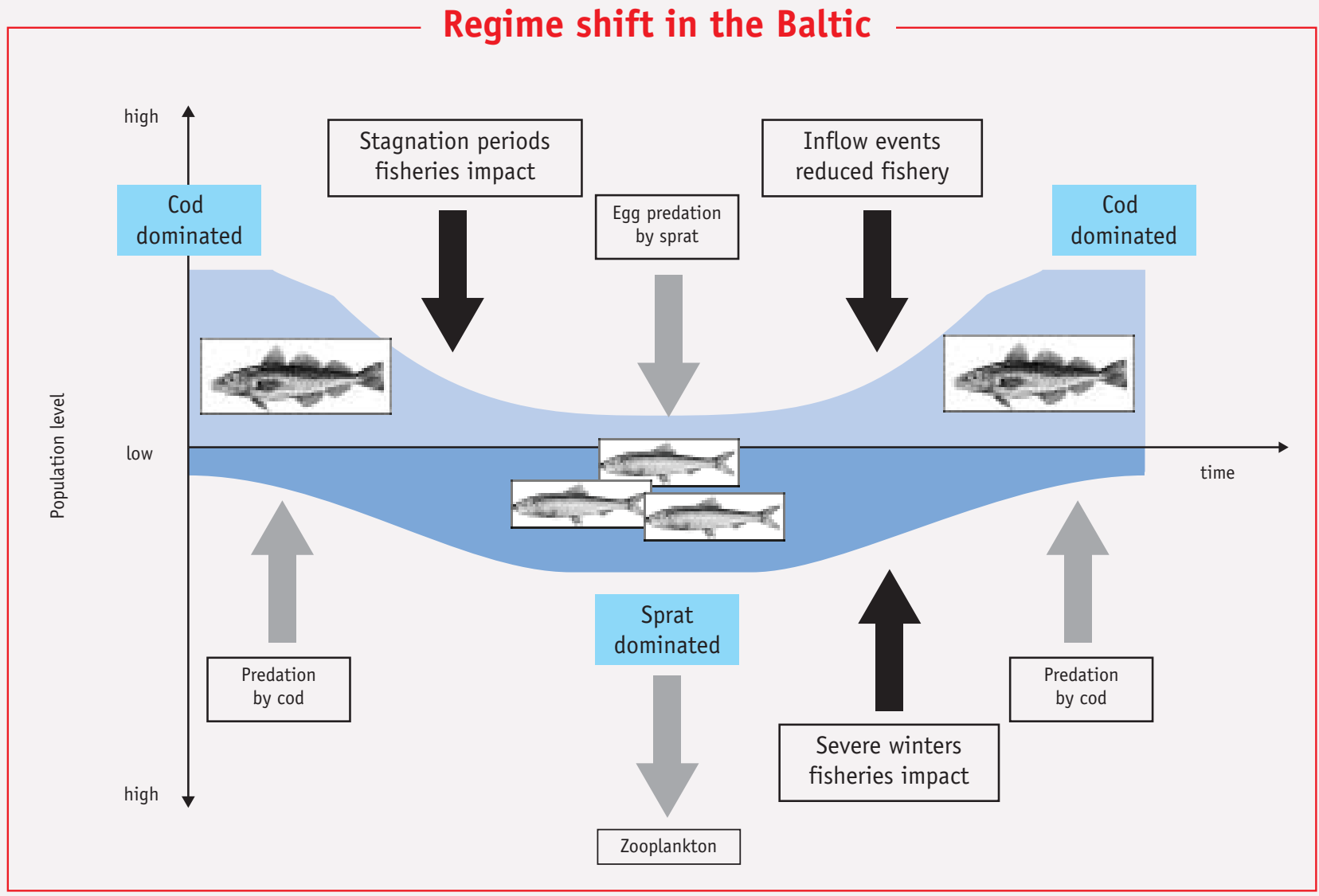

Figure 24 Changes in salinity and water temperature in the Baltic Sea affect the life histories of the two main fish species, cod and sprat, by affecting egg mortality (cod) or prey abundance (sprat). Fishing pressure and interspecific predation also play a role. As a result, the two species alternate in dominance over time.

Source: Köster et al. (2001) IGBP Newsletter 46: 16-18 



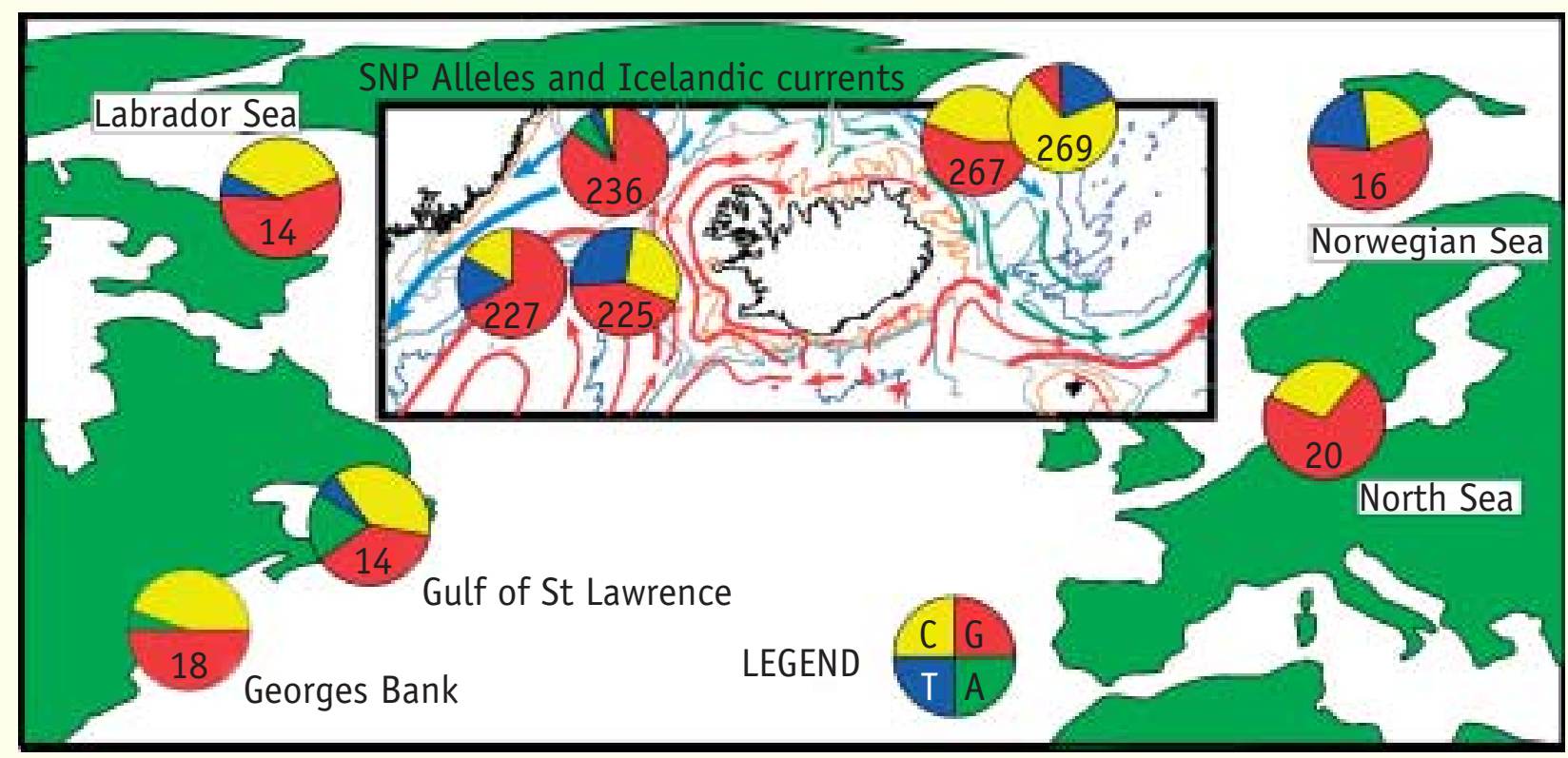

Figure 25 Population genetic diversity and structure of the copepod Calanus in the $\mathrm{N}$ Atlantic Ocean can be described using variation at single sites in the DNA sequence, such as one in an enzyme-encoding gene, where any of the four nucleotide bases (G, C, T, A) may occur.

Source: Adapted from Bucklin et al (2000) ICES J. Mar. Res. 57: 1592-1604

life stage (Fig. 25). Molecular systematic assessment of marine animals helps to define species boundaries, reveal cryptic species, identify morphologically-indistinguishable taxa (for individuals, pooled samples and gut contents), and accurately estimate biodiversity.

Population genetic analyses of highly abundant and geographically widespread organisms (such as zooplankton and both larval and adult fish) are important for revealing underlying population dynamics (patterns of recruitment, dispersal, and mortality). They may also reveal the species' evolutionary history and responses to climatic variability. Techniques such as mitochondrial DNA (mtDNA) sequence variation, single nucleotide variation, and microsatellite genetic markers have been used successfully to infer historical fluctuations in population size for sardines, anchovies and copepods, to discriminate between different populations of cod and copepods and to link individual fish to their original population.

New techniques also enable molecular and DNA studies of specimens that have been preserved in formalin, something that was not previously possible.These studies should encourage retrospective studies entailing molecular analysis of archived oceanographic samples.

Miniaturisation and automation are becoming standard in molecular laboratories."Lab on a chip" technologies will increasingly make it possible to conduct molecular assays remotely using apparatus on moored or autonomous instrumentation deployed anywhere in the worlds ocean. Rapid advances in genomics (the study of genes and their functions) and analysis of gene expression (creation of proteins from genes) are also extending to marine animals.

\section{New video technologies}

Predicting the impact of environmental change on marine life depends on the development of a quantitative understanding.This is difficult, given the inherently large variability of the system and our limited ability to sample it in time and space. However, new sensors and platforms for deploying high-resolution sampling systems are being developed that will enable oceanographers to map 3-D distributional patterns of marine populations autonomously in real time over large areas. The resulting data is being incorporated into dataassimilative models for forecasting population trends and impacts of environmental change.

The Video Plankton Recorder (VPR, Fig. 26) is essentially an underwater video microscope that images, identifies, counts and sizes plankton and other particles in the size range of $100 \mu \mathrm{m}$ to $5 \mathrm{~cm}$, while an analysis programme on board the ship matches this information with concurrent navigational and environmental data. In addition, the VPR data can be coupled to acoustic instru- 



Figure 26 The new digital Video Plankton Recorder (VPR) being retrieved during a test cruise on the Japanese fisheries research vessel R/V Shunyo maru, June, 2001. The VPR uses a 1 mega-pixel 10-bit camera to capture high-resolution images of plankton and seston, and to quantify and measure the species it sees in real time.

Source: Photo courtesy of Scott Gallager.

ments, providing ground-truthing to acoustical signals by direct identification of the organisms ensonified.

New VPR deployment platforms include mechanisms that allow high-speed towing (10 knots) out of the wake of the ship, a moored autonomous profiler to obtain high-resolution time series of water column plankton, and autonomous underwater vehicles to enable robotic spatial sampling of plankton and environmental variables. Another example is a novel real time shipboard fish egg sampling device (Continuous Underway Fish Egg Sampler), which has been developed and used to rapidly map fish egg distributions over broad areas (Fig. 27).

\section{New hydroacoustic tools}

One of the goals of the SO GLOBEC programme (see Box 2) is to determine the abundance and distribution of Antarctic krill.Hydroacoustic surveys with a Bio-Optical Multi-frequency Acoustical and Physical Environmental Recorder (BIOMAPER-II) system provide a means for obtaining this information. The BIOMAPER-II system consists of: a multi-frequency sonar, with centre frequencies of $43 \mathrm{kHz}, 120 \mathrm{kHz}, 200 \mathrm{kHz}, 420 \mathrm{kHz}$, and $1 \mathrm{MHz}$; a Video Plankton Recorder and an environmental sensor package consisting of conductivity-temperature-depth sensors; a fluorometer; and a transmissometer. Data are collected from these sensors as the BIOMAPER-II is

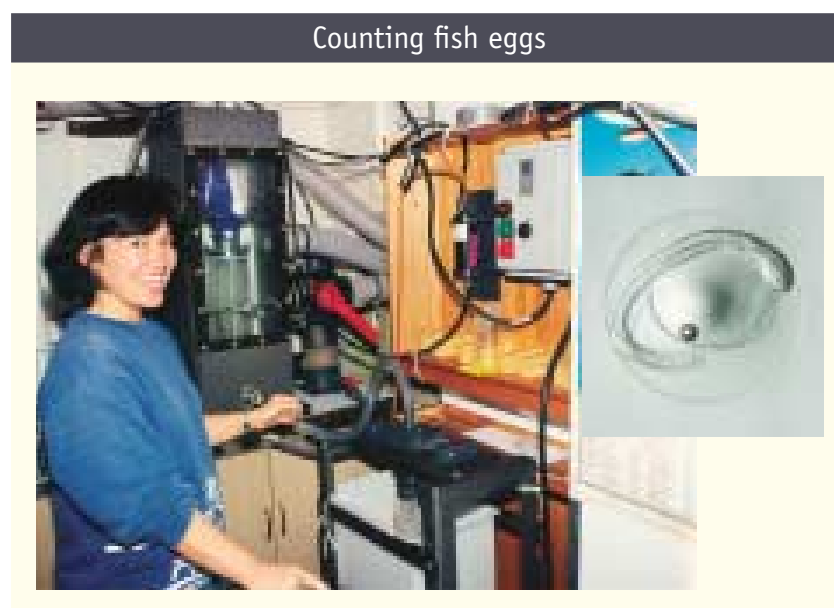

Figure 27 Operating the Continuous Underway Fish Egg Sampler (CUFES) on board a GLOBEC research cruise off Peru, and a sample of CUFES: a menhaden egg. Measurements of the distribution and abundance of fish eggs can then be related to environmental conditions to improve our understanding of the factors influencing fish life histories.

Source: Dave Checkley towed along the cruise track lines. The use of BIOMAPERII as a primary data gathering instrument in SO GLOBEC marks the first time that this type of multi-frequency environmental sampling system has been used to study the pelagic zone in Antarctic waters.

The hydroacoustic observations from the individual track-lines are combined to provide three-dimensional renderings of the scattering record. The acoustic scattering at specific frequencies is indicative of particular

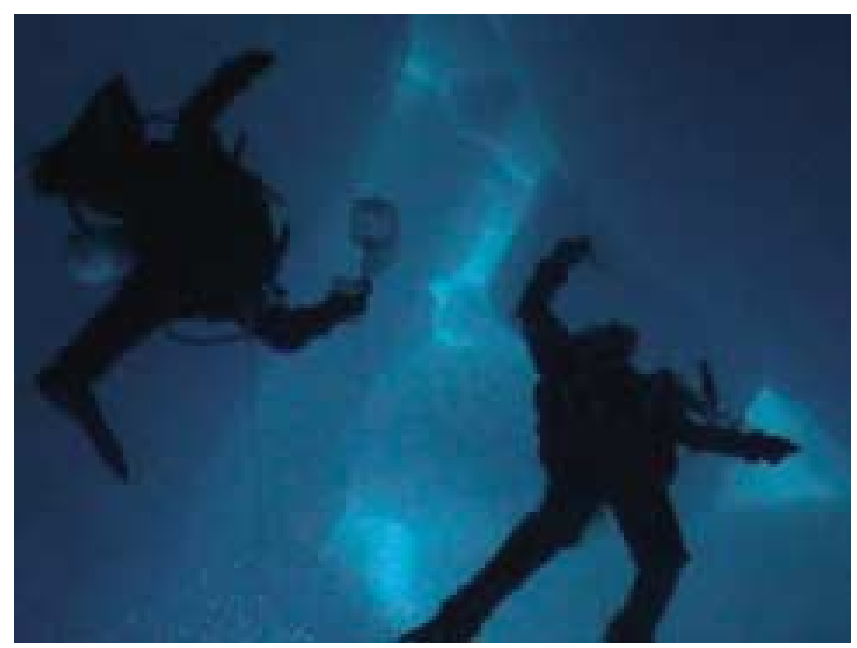

Under-ice diving to collect juvenile Antarctic krill with small plankton nets. The krill will be kept in the laboratory in order to study their physiology.

Source: Stian Alesandrini. 


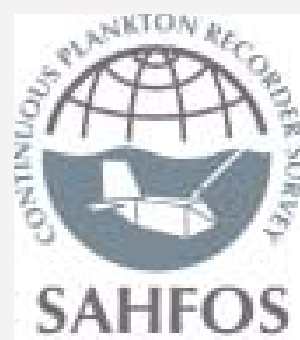

In the early 1930s Sir Alister Hardy conceived a survey designed to "study the broad changes taking place in the plankton distribution of the North Sea and their relation to the changing hydrological and meteorological conditions on the one hand, and with the fluctuations in the fisheries on the other." Sir Alister believed that the changing plankton needed to be studied in a way similar to that used by meteorologists to study the weather, so he designed the CPR to carry out the survey. Today, the survey is still running and its geographical limits extend far beyond those of the North Sea, to the whole of the North Atlantic Ocean.

The CPR is a self-contained, automatic plankton sampler about $1 \mathrm{~m}$ long towed by commercial ships at a depth of about $7 \mathrm{~m}$. The CPR works by filtering plankton from the water on a constantly moving band of silk. Its robust design allows it to be towed at speeds of up to 22 knots and in rough seas. Using this simple but highly cost-effective device, over four million nautical miles have been towed by volunteer ships, collecting nearly 200,000 plankton samples from all over the North Atlantic. The groups counted include approximately 400 taxa of phytoplankton and zooplankton, as well as a visual index of chlorophyll. The CPR data set is thus the single largest plankton data set in the world.

species, such as Antarctic krill at $120 \mathrm{kHz}$. Remote hydroacoustic observations are complemented with ship-board laboratory studies on the physiology, biology

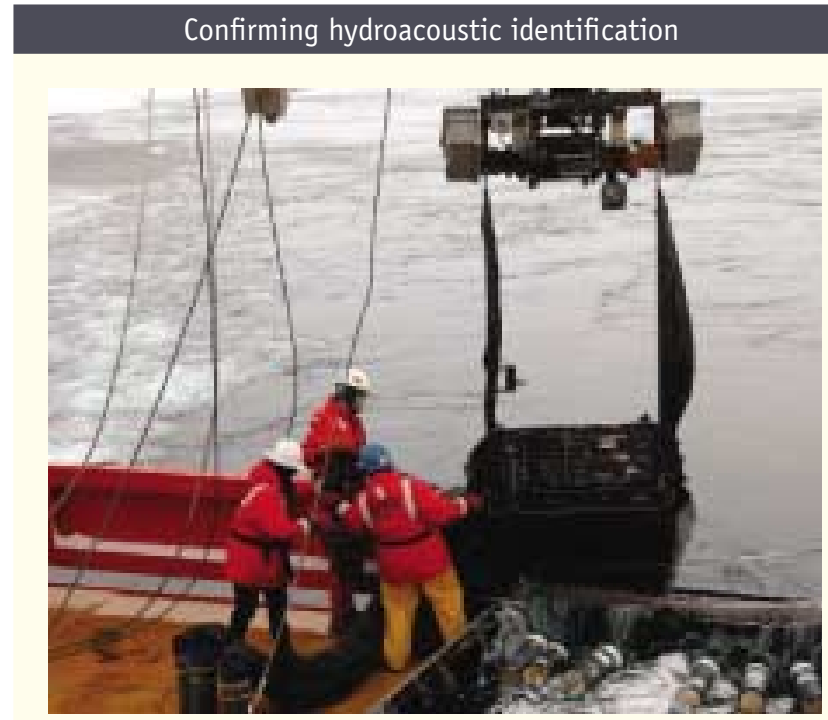

Figure 28 Recovering the $1 \mathrm{~m}^{2}$ MOCNESS nets over the stern of the RVIB Nathaniel B. Palmer. Divers and MOCNESS catches confirm the species identification of BIOMAPER echoes.

Source: Peter Wiebe.



The Continuous Plankton Recorder has been used for 70 years to collect a valuable long-term time series of plankton in the North Sea and the North Atlantic. Such long time series are rare, but extremely useful, as they enable present day changes to be put in a historical context.

Source: The Sir Alister Hardy Foundation for Ocean Science.

The CPR survey is now operated by the Sir Alister Hardy Foundation for Ocean Science (SAHFOS), an international charity affiliated to GLOBEC.

and ecology of krill and zooplankton, as well as underice diving to characterise the sea ice habitat and sea ice biota, and net sampling using Multiple Opening/ Closing Net and Environmental Sampling Sensing System (MOCNESS) net tows (Fig. 28).When the results of these methods are combined, they can be used to determine distribution, abundance and variability of the pelagic community assemblage. Preliminary results from the hydroacoustic BIOMAPER-II surveys are already modifying ideas about how Antarctic krill are distributed and survive in the waters of the western Antarctic Peninsula continental shelf during the austral winter.

\section{Modelling: from the individual to populations}

Modelling and prediction are core GLOBEC activities. Modelling is essential for forecasting future states of marine ecosystems and/or to examine hypotheses of ecosystems' responses to global change. Modelling integrates understanding of field observations, laboratory experiments, theory and computation within a wide range of physical and biological processes. Specifically, GLOBEC modelling activities are directed at identifying key mechanisms linking physical and biological (includ- 
Figure 29 Observed distribution of species (left), model formulation approach (centre) leading to increased complexity at higher trophic levels, and suggested middle-out approach (right). In the middle-out approach, the focus is placed first on the level of primary interest, with decreasing resolution in the links up to predators and down to prey.

Source: Adapted from the ICES Study Group on Spatial and Temporal Integration, Glasgow, 1993 (ICES C.M. 1993/L:9).

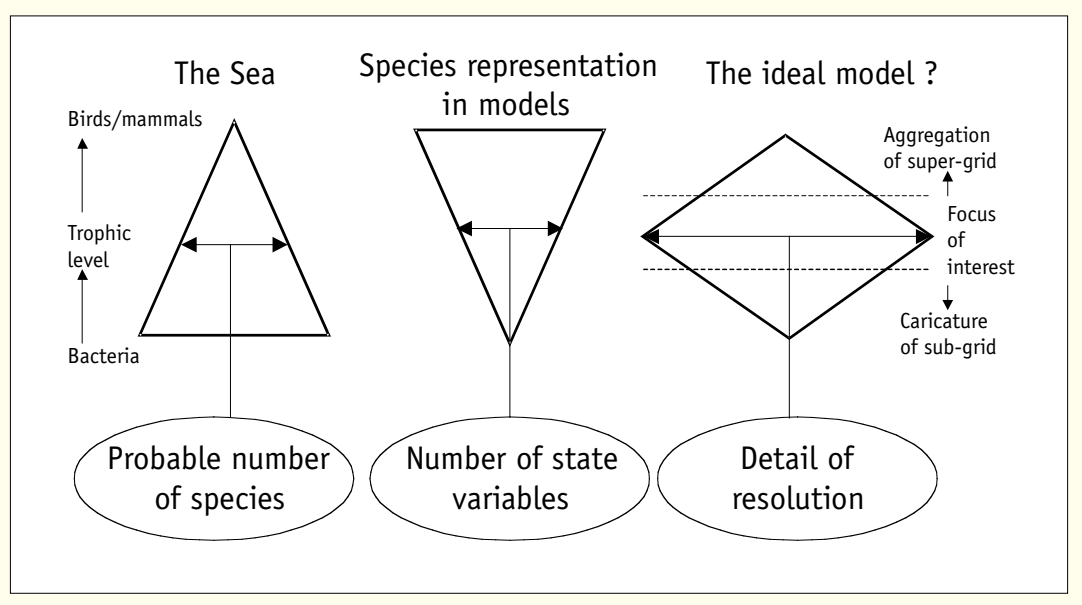

ing behavioural) components of the marine ecosystem and the impacts of human exploitation on these.

Additionally, motivated by observed decadal changes in fished stocks such as cod, herring and salmon species, GLOBEC is developing an understanding of fisheries fluctuations at basin scales. However, the problem is of such magnitude that no single model, or modelling approach can include all relevant processes.As such, the approach is to develop a hierarchy of targeted models.A "middleout" approach (Fig. 29) is followed, where the focus is placed first on the taxa or trophic level of primary interest, with decreasing resolution in the links up to preda- tors and down to prey. The effort in constructing such models focuses on the target species and in achieving adequate parameterisations of the processes and interactions with the neighbouring levels (Fig. 30).

GLOBEC's focus on target species means that it is essential to understand the individual organism (its life cycle, behaviour and physiology) as well as its interactions with its environment (Fig. 33). As such, the use of spatially explicit individual based models (IBMs) has become a de facto tool in initial GLOBEC modelling studies. The utility of IBMs is that properties of ecological systems can be derived by considering the properties
Figure 30 The flowchart for a larval cod trophodynamics model. Included are the effects of light, prey type/size and turbulence on encounters, capture and satiation, and the effects of temperature on growth.

Source: Courtesy of John A. Quinlan

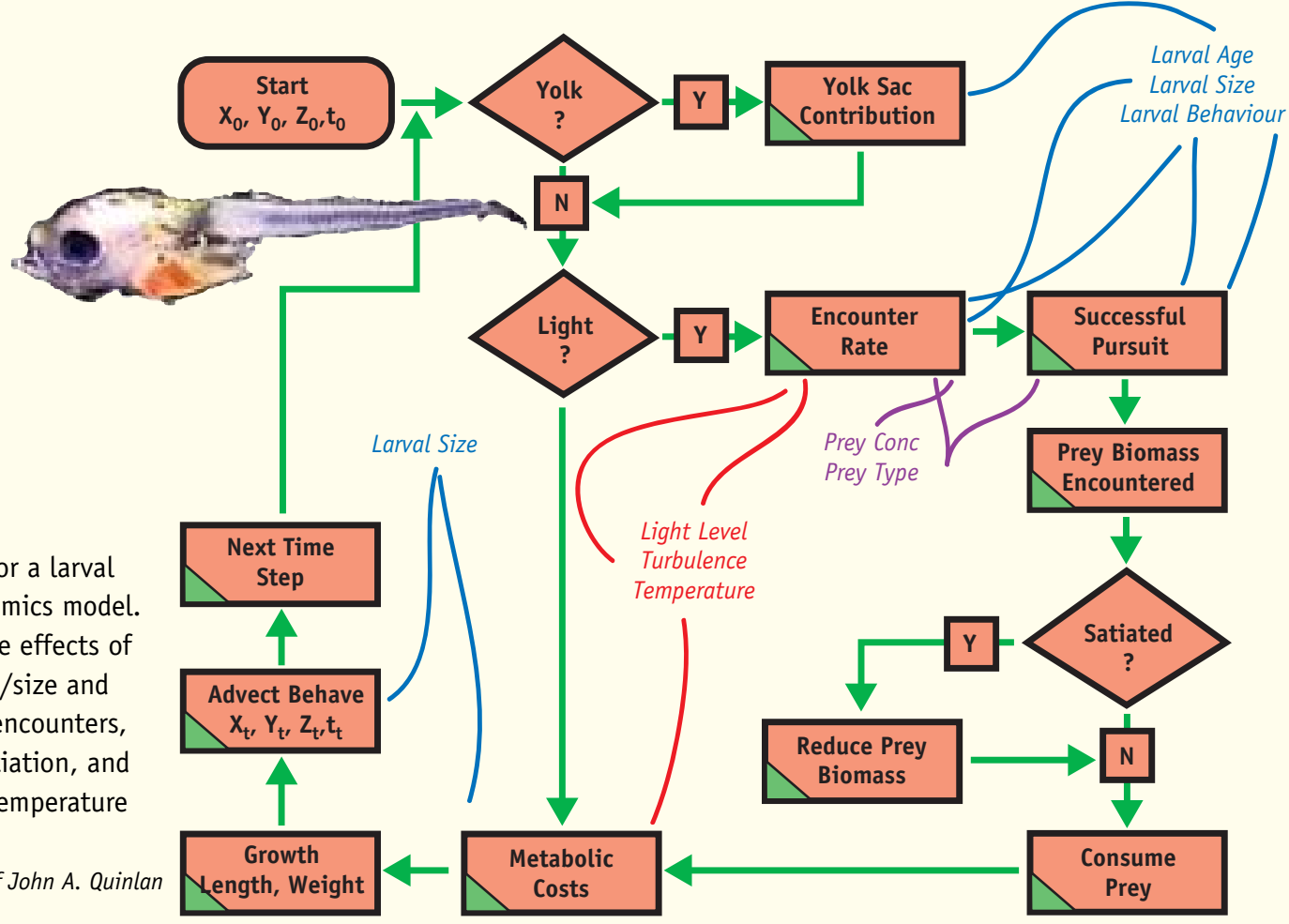


of individuals constituting them. Individual differences may be behavioural, physiological, or may arise from interactions among individuals. The differences result in unique life histories, which when considered as a whole give rise to growth and size distributions that provide a measure of the state of the population.

The spatial distribution of species abundance is a key focus of GLOBEC models, including the response of populations to horizontal spatial heterogeneity.This might include basin models of euphausiids crustacean in the Antarctic Circumpolar Current, clupeid fish populations in Eastern Boundary Current Systems, gadoids fish in the North Atlantic, or the extinction of loosely linked salmon populations related to changes in conditions in the North Pacific or the California Current.

Models of early life histories of target species have coupled advanced ocean circulation models and field data to include the effects of realistic temporal and spatial variation of currents, turbulence, light, prey, etc., on their behaviourally modified trajectories and growth. The result is an improved understanding of the recruitment process through the determination of retention and loss mechanisms, as well as food limitation (Fig. 30).
Individual Based Models (IBM) can be used to investigate the dynamics of different spatial and temporal spawning patterns and transport of fish eggs and larvae. IBMs allow the integration and visualisation of environmental, ecological and biological information. They are widely used in ecology, particularly in the field of marine ecology, and they complement classical fish population dynamics models.

IBMs have been successfully used to provide a 3-D world in which it is possible to explore the dynamics of anchovy (Engraulis capensis) recruitment off South Africa, where these fish are an important component of the fishery. Understanding their spawning and recruitment dynamics is crucial for fisheries management. Adult anchovy spawn serially during austral spring and summer on the Agulhas Bank, the broad continental shelf south of the country (Fig. 31). Eggs and larvae are rapidly transported northwards along the West Coast by frontal jet currents, and cross the wide shelf to a nursery region close inshore along the west coast, before moving southwards towards the Agulhas Bank to spawn when one year old.

In the model, virtual eggs were released from five differ-

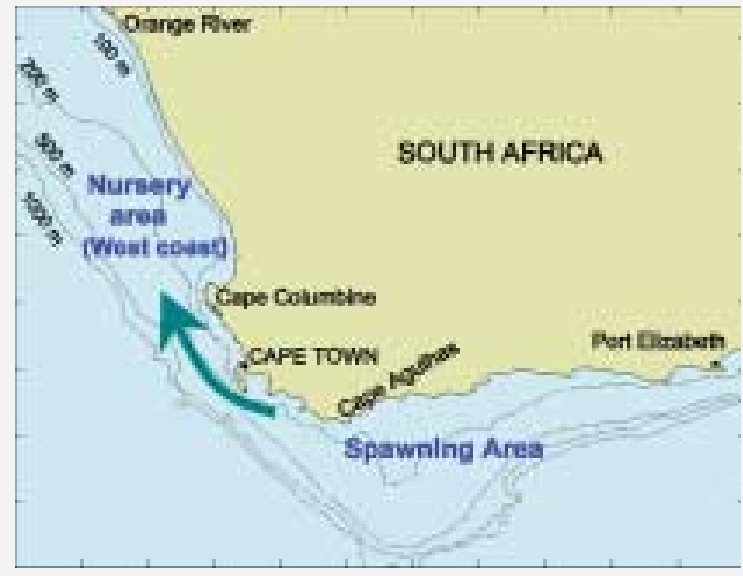

Figure 31 Adult anchovies spawn on the Agulhas Bank off South Africa. This area was chosen as a site to develop models of egg transport at different times of the year. The arrow represents the shelf-edge jet current.

Source: Pierre Freon. ent spawning areas on the Agulhas Bank (Fig. 32) during each month of the year. Other variable parameters included egg patchiness, spawning frequency and the year of the simulation model. Transport success was defined as particles that were passively transported to and retained in the nursery area within a pre-defined time frame. The simulations in Fig. 32 show the complex paths of particles in the hydrodynamic flows of the Benguela system.

This experiment identified the optimum place (western Agulhas Bank) and time of year (September to March) for spawning, which matched well with field observations. Transport success was low, suggesting that additional processes are required for larvae to reach the inshore nursery area. Simulations incorporating other parameters, such as egg density and later stages of development, are currently being implemented by GLOBEC scientists, as well as an evolutionary IBM exploring different natural selection scenarios and their implications for spawning behaviour.

Figure 32 Output from an IBM simulation map on the 15th December (top), 15th January (centre) and 1st February (bottom) of 25000 particles (in white, representing fish eggs) released in one of the spawning areas off South Africa's south coast, and passively transported by currents provided by a 3-D hydrodynamic model. Source: Courtesy of $C$. Mullon and the IDYLE group (http://sea.uct.ac.za/idyle/)

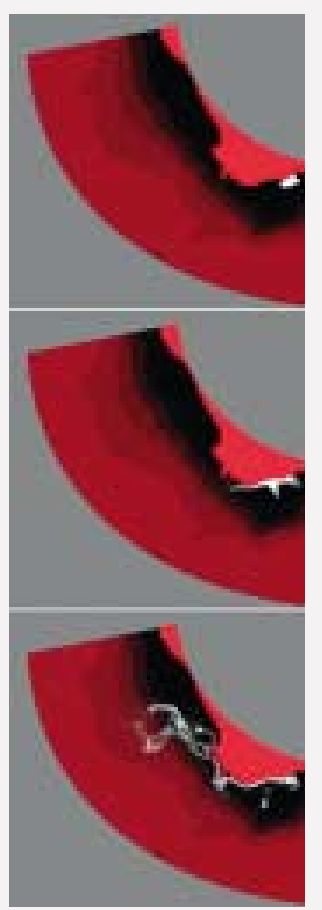




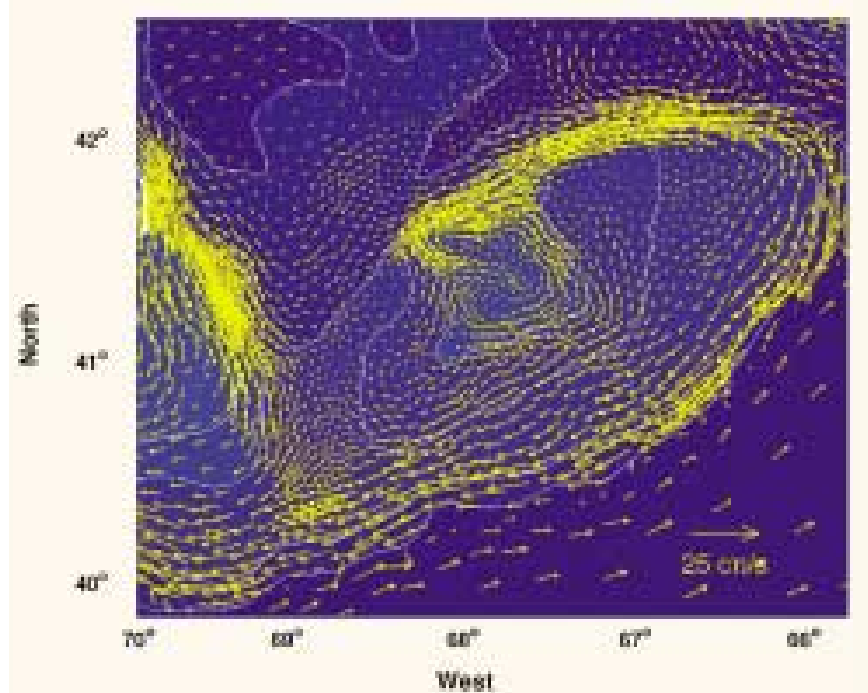

Figure 33 The left image shows mean March-April ocean circulation on Georges Bank, NE USA, averaged over all depths. The ocean circulation model is then used to simulate the transport paths of larvae during the 60-days after spawning over a fixed area (right). Larvae spawned at depth and straddling the $60 \mathrm{~m}$ depth contour are retained in the area. Larvae near the surface and seaward of the
Day 0 - Soawn

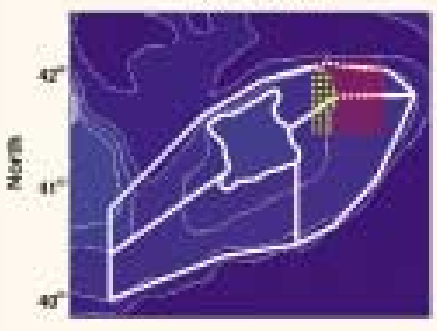

Ding 40

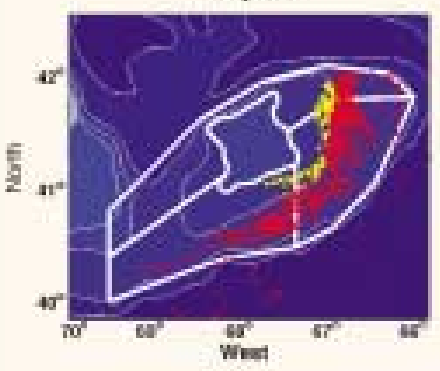

Day 20 - Hatch

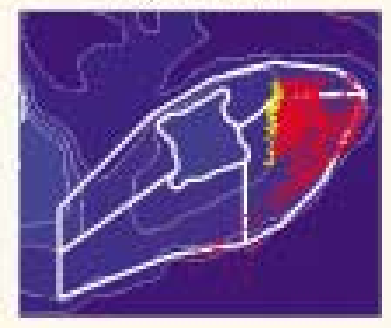

Dey 60

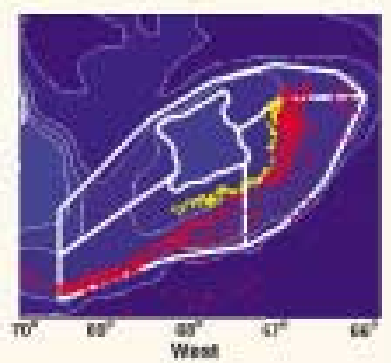

$60 \mathrm{~m}$ depth contour are lost due to advection. Near the top of the bank, food limitation and turbulence limit larval growth. Source (left): Reproduced by permission of the American Geophysical Union from Naimie (1996) J. Geophys. Res. (Oceans) 101: 6469-6486 Source (right): Reproduced with permission from Werner et al. (2001) Scientia Marina 65: 99-115 


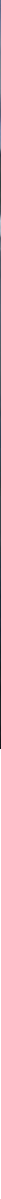



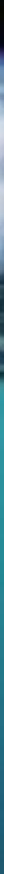

\section{About GLOBEC}

GLOBEC is structured around four major research Foci, which are common to all field activities. Each Focus is steered by a working group whose aim is to bring together the achievements of the field programmes into a coherent summary of GLOBEC's achievements. This structure is designed to assist in the synthesis and integration of the project.
GLOBEC conducts research on the structure and functioning of marine ecosystems and the forces impacting these: atmosphere and ocean climates, resource exploitation and global change.

Source: Original illustration by Glynn Gorick/ GLOBEC IPO
AT THE BASE OF GLOBEC sit the field activities, at national, multinational and regional levels (Fig. 34). National and multinational activities are dynamic, time-limited, and under constant update. Regional programmes are major initiatives, both in time and space as well as in scientific complexity. GLOBEC is currently implementing four regional programmes: two (Small Pelagic Fish and Climate Change -SPACC, and Southern Ocean GLOBEC) are field programmes under the direct responsibility of the GLOBEC Scientific Steering Committee. The other two, PICES-CCCC (PICES-Climate Change and Carrying Capacity) and ICES-CCC (ICES-Cod and Climate Change), are largescale studies, each confined to a single ocean basin and co-ordinated by regional science organisations, in very close cooperation with GLOBEC. More information on these activities is available on the GLOBEC website (http://www.globec.org).

The activities and the outputs of the different national, multinational and regional activities, are integrated in coordination with GLOBEC's Foci working groups, and are steered by an international Scientific Steering Committee, whose members are appointed for 3-year terms by GLOBEC's sponsors, the Scientific Committee on Oceanic Research, the International Geosphere-Biosphere Programme and the Intergovernmental Oceanographic Commission of UNESCO. The implementation of the whole programme is coordinated through an International Project Office hosted by the Plymouth Marine Laboratory in the UK. 


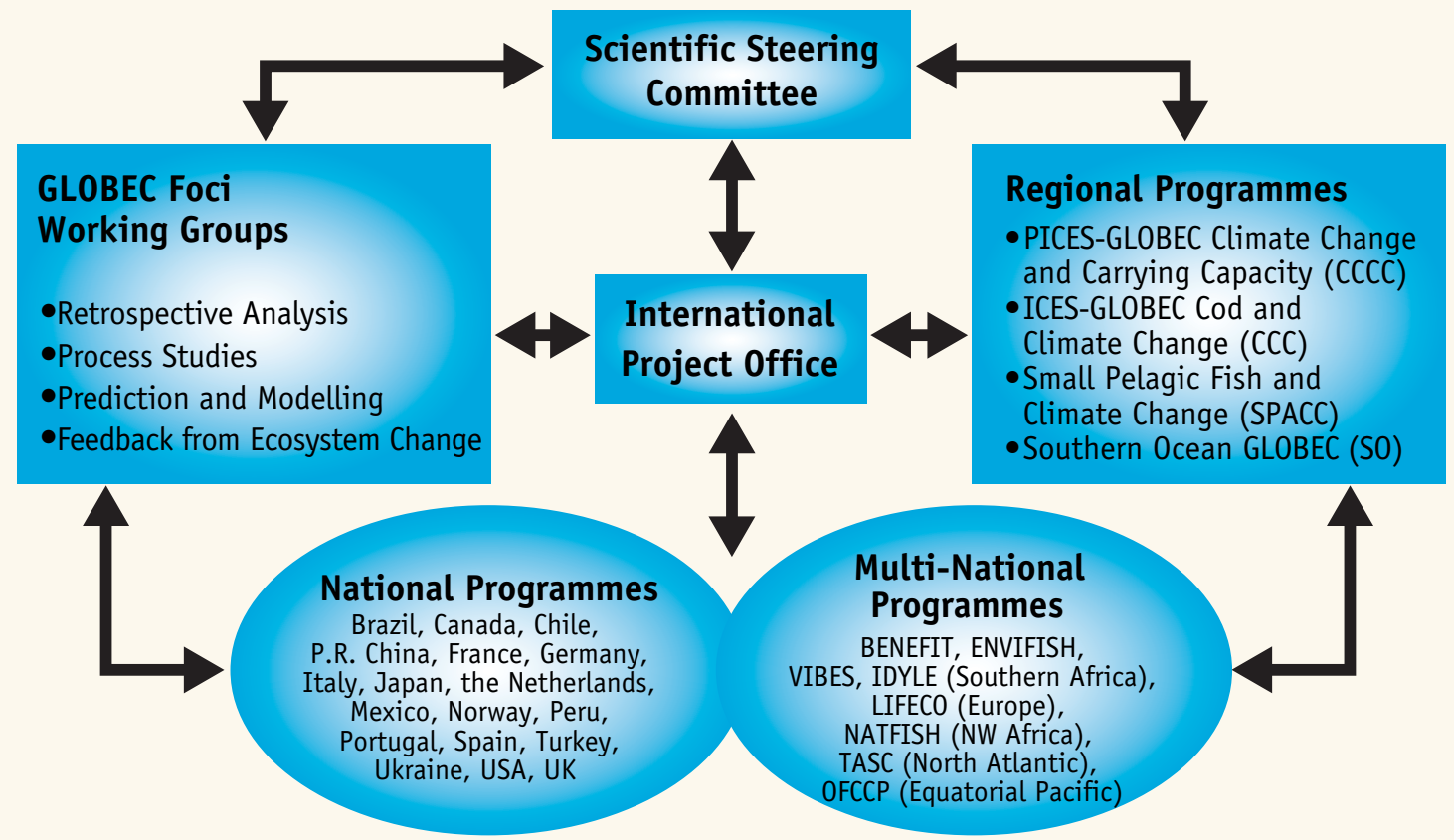

Figure 34 GLOBEC consists of national, multinational and regional field programmes, coordinated through a scientific steering committee and supported by a number of working groups and an international project office. GLOBEC is sponsored by the International Geosphere-Biosphere Programme (IGBP), the Scientific Committee on Oceanic Research (SCOR) and the Intergovernmental Oceanographic Commission (IOC).

\section{Data management}

GLOBEC has established a data policy intended to augment the long-term success of the project, ensuring that valuable data collected by researchers are properly and effectively utilised.The key points of the policy are data and metadata sharing, responsible archiving of data and inventory, and cataloguing of activities.

GLOBEC uses a decentralised data management and distribution system. The central component is a comprehensive inventory of GLOBEC and GLOBEC-related metadata with pointers to the data location and key contact persons. This inventory is based on the Directory Interchange Format (DIF). Each GLOBEC activity constructs a DIF file or provides sufficient data to allow the IPO to construct a DIF. Metadata supplied to the IPO includes the following variables: dataset name, dataset description, data coverage (spatial and temporal), data attributes (parameters), contributors including contact information, source of data, project/campaign name, data location and distribution information, relationship of data to other versions of the dataset and references. DIF files are stored in the NASA-based Global Change Master Directory (GCMD) database to ensure long-term stewardship. This data is accessible both through the GCMS webpage and through a dedicated GCMD portal in the GLOBEC website.

\section{Publications}

GLOBEC researchers have published hundreds of peerreviewed articles in the main scientific literature. References for these are accessible through the GLOBEC website. The GLOBEC International Project Office also publishes a sixmonthly GLOBEC Newsletter, a

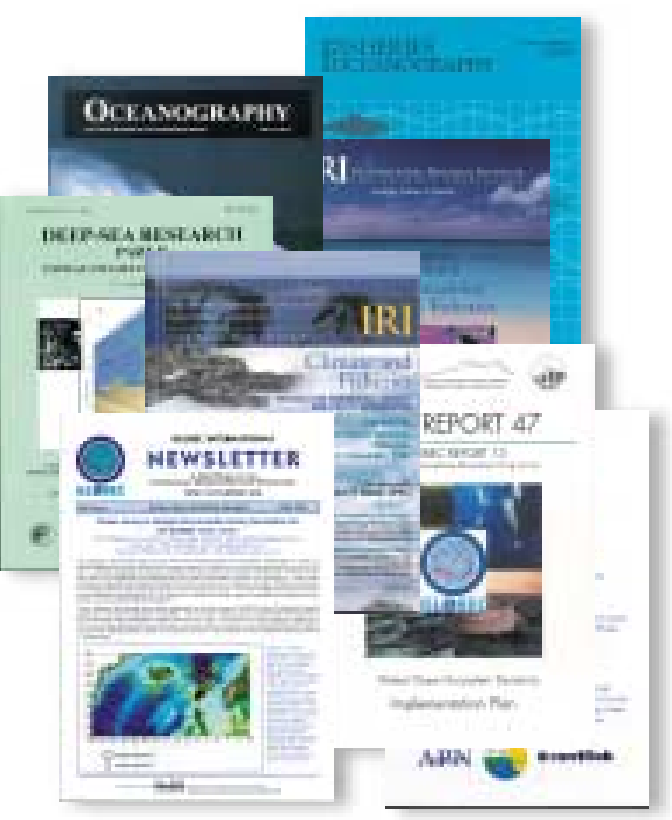
GLOBEC Report Series and a GLOBEC Special Contribution Series, to communicate GLOBEC's research to the scientific, managerial and policy-relevant communities. Special publications in journals such as Deep Sea Research II (1996, 43(7-8); 2001, 48(1-3)) and Fisheries Oceanography (1998, 7(3-4); 2002, 11(6)) are often commissioned. Digital CDs of metadata and publication records are also produced by the IPO and distributed freely. 
Editors: Manuel Barange and Roger Harris.

Series Editor: Clare Bradshaw with editorial assistance from Susannah Eliott and Angelina Sanderson (IGBP Secretariat).

Acknowledgements: Wendy Broadgate, Will Steffen.

Layout: Idéoluck AB, Stockholm. Cover design and technical support by John Bellamy.

Scientific contributors: Jürgen Alheit,Andrew Bakun, Manuel Barange, Harold P. Batchelder,Tim Baumgartner, Gregory Beaugrand, Keith Brander, Ann Bucklin, Philippe Cury, Cabell Davis, Pierre Fréon, Eberhard Hagen, Roger Harris, Mike Heath, Hans-Harald Hinrichsen, Eileen Hofmann, Jenny Huggett, Suam Kim, Shingo Kimura, Leonid Klyashtorin, Fritz W. Köster, G. Kraus, Patrick Lehodey, David Mackas, Arthur Miller, Christian Möllmann, Christian Mullon, Steve Nicol, Rosemary Ommer, Carolina Parada, Pierrick Penven, R. Ian Perry, Andrew Pershing, Sergey Piontkovski, Benjamin Planque, Anthony Richardson, Zina Romanova, Claude Roy, D. Schnack, Michael St. John, P.Ted Strub, Ulrich Struck, Svein Sundby, Jefferson T.Turner, Carl van der Lingen, Francisco Werner.

Project Sponsors: IGBP, SCOR, IOC.

Cover image: Illustration by Glynn Gorick, GLOBEC

Inside front cover: Photo by Manuel Barange 


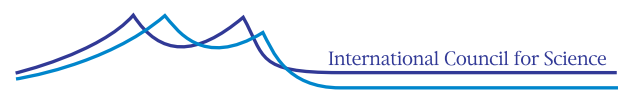

Scientific Committee on Oceanic Research
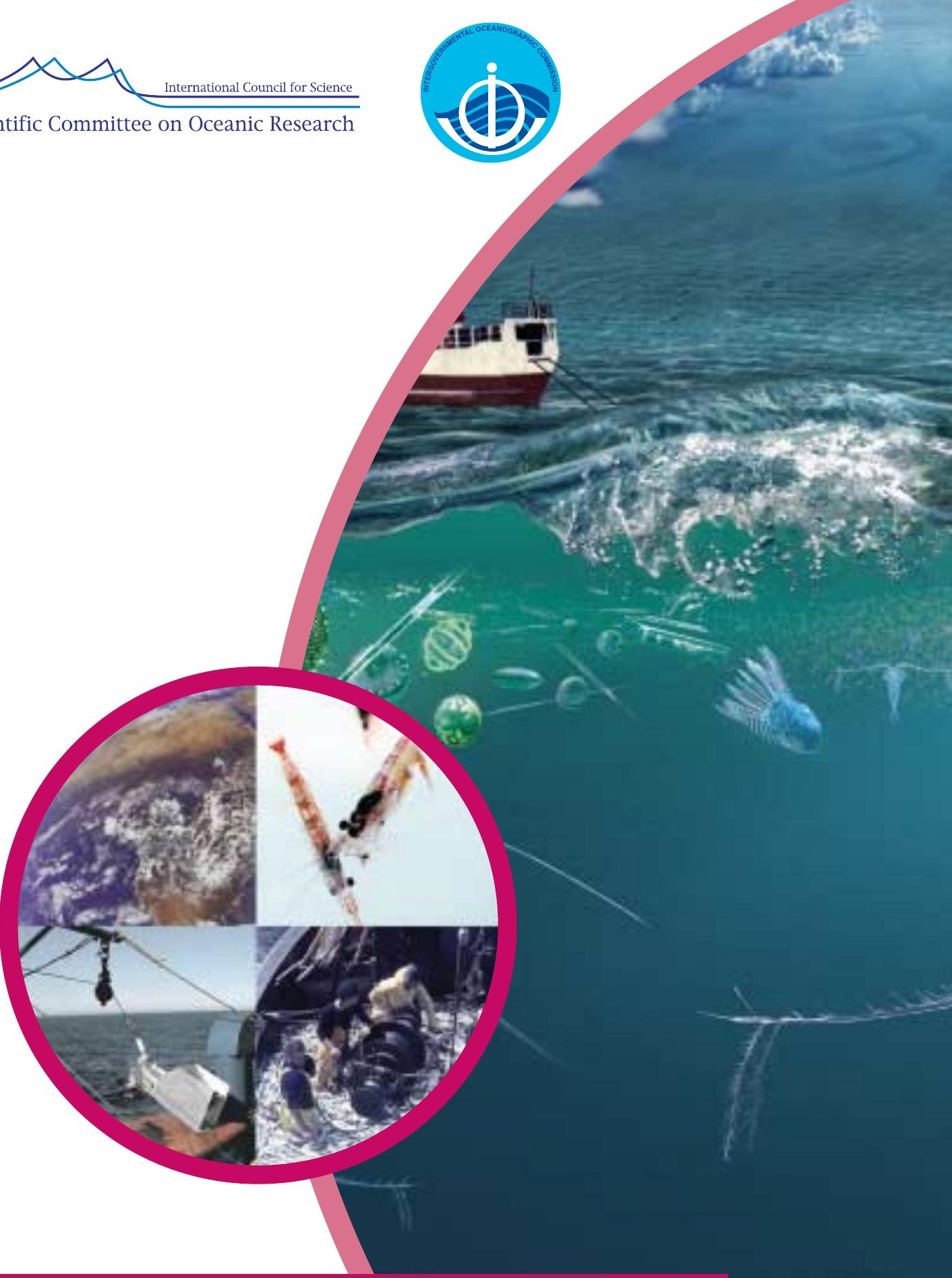

CHANGES ARE OCCURRING IN THE OCEANS, increasingly due to human impacts on the Earth System. These changes affect everything from simple processes, such as the hatching of a single species' eggs, to complex processes affecting biodiversity and the functioning of ecosystems. By understanding the detailed processes affecting marine organisms and their life histories, we can understand how individuals and populations adapt to changing environments. Separating the impacts of long-term change from natural variability enables causes to be identified, and future patterns to be predicted. Marine ecosystems' responses to the changing oceans have important implications for fisheries and food supply, as well as for the functioning of the planet as a whole.

The IGBP Science Series is designed to make IGBP's research output accessible to a wider range of audiences, in particular to the policy and resource management communities. These visually rich reports present the most recent scientific understanding in major areas of Earth

- System Science.

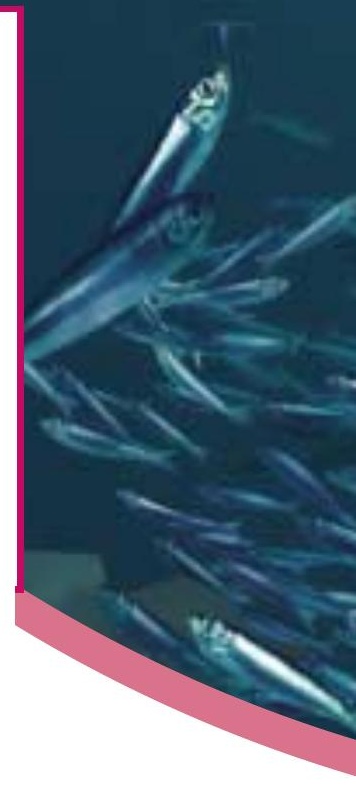

